\title{
Udoteaceae (Bryopsidales, Chlorophyta) no litoral do estado da Bahia, Brasil
}

\author{
Gabriel do Nascimento Santos ${ }^{1,2^{*}} \&$ José Marcos de Castro Nunes ${ }^{1,2}$ \\ ${ }^{1}$ Programa de Pós-Graduação em Botânica, Departamento de Ciências Biológicas, Universidade Estadual de \\ Feira de Santana, Bahia, Brasil. \\ ${ }^{2}$ Laboratório de Algas Marinhas (LAMAR), Departamento de Botânica, Instituto de Biologia, Universidade \\ Federal da Bahia, Salvador, Brasil.
}

\begin{abstract}
Resumo - As Udoteaceae são ubíquas e ecologicamente importantes em ecossistemas marinhos tropicais. Além de produtores primários, os representantes calcificados contribuem na construção e sedimentação dos recifes. Neste estudo, apresentamos o tratamento taxonômico da família Udoteaceae no litoral da Bahia. A partir de coletas e de material depositado nos principais herbários brasileiros, foram reconhecidos 10 táxons infragenéricos distribuídos em três gêneros: Boodleopsis (B. pusilla), Penicillus ( $P$. capitatus, com três formas) e Udotea (4 espécies, 2 variedades e 2 formas). São apresentadas chaves de identificação para os táxons, além de descrições, ilustrações, comparações com táxons relacionados e mapas de distribuição na Bahia para cada espécie.
\end{abstract}

Palavras-chave adicionais: algas calcárias, biodiversidade, morfologia, Nordeste, taxonomia.

\begin{abstract}
Udoteaceae (Bryopsidales, Chlorophyta) from the coast of Bahia State, Brazil) - The Udoteaceae are ubiquitous and ecologically important in tropical marine ecosystems. Apart from primary producers, calcified representatives contribute to the construction and sedimentation of reefs. In this study, we present the taxonomic treatment of Udoteaceae from Bahia coast. Based on collected material and on material deposited in the main Brazilian herbaria, 10 taxa, distributed in three genera, were recognized: Boodleopsis (B. pusilla), Penicillus (P. capitatus, including three forms), and Udotea (4 species, 2 varieties, and 2 forms). Identification keys for the taxa are presented, along with descriptions, illustrations, comparisons with related taxa, and distribution maps for species in Bahia.
\end{abstract}

Additional key words: biodiversity, calcareous algae, morphology, Northeast Brazil, taxonomy.

As algas verdes marinhas representantes da ordem Bryopsidales (Bryopsidophyceae) possuem arquitetura sifonada (Hillis-Colinvaux 1986), basicamente formada por um sistema ramificado de filamentos cenocíticos, que varia de uma a várias camadas de sifões ramificados que se entrelaçam aos sifões adjacentes, podendo ser densamente atrelada a frouxa. $\mathrm{Na}$ maioria dos grupos, há ramificações laterais nos sifões terminando em apêndices, utrículos ou tenáculas, que recobrem os sifões mais internos e/ou consolidam o talo. Em muitos representantes, os espaços entre os sifões tornam-se calcificados nas partes do talo que estão acima do substrato (Borowitzka \& Larkum 1977). Embora estruturalmente simples, as Bryopsidales apresentam uma grande diversidade morfológica, desde estruturas menos complexas, formadas por apenas um sifão, até um sistema elaborado e denso de sifões emaranhados e aderidos entre si (Lam \& Zechman 2006), exibindo uma grande diversidade de talos e várias especializações morfoecológicas (Verbruggen et al. 2009).

A família Udoteaceae é uma das mais diversificadas dentre as Bryopsidales, estando representada por 15 gêneros, seis deles no Atlântico Oeste: Boodleopsis A.Gepp \& E.Gepp, Penicillus Lam., Pseudocodium

\footnotetext{
*Autor para correspondência: gabrieldonascimentosantos@yahoo.com; ajmcnunes2000@gmail.com

Editor responsável: Alessandro Rapini

Submetido: 6 jun. 2014; aceito: 7 nov. 2014

Publicação eletrônica: 11 nov. 2014; versão final: 23 dez. 2014
}

Weber Bosse, Rhipidosiphon Mont., Rhipocephalus Kütz., e Udotea J.V.Lamour. (Wynne 2011). Seus representantes são ubíquos e ecologicamente importantes em ecossistemas marinhos tropicais (Clifton \& Clifton 1999) como produtores primários e também na consolidação e formação dos sedimentos superficiais marinhos (Cabrera \& Alfonso 2010). Na maioria dos representantes desta família, existem apressórios do tipo bulboso estruturalmente formados por um emaranhado de pequenos e numerosos sifões que agregam e consolidam o substrato arenoso (Littler \& Littler 1992). Os representantes calcificados, como Udotea e Penicilus, são importantes no sequestro de carbono, fundamentais para o balanço das concentrações do gás carbônico atmosférico (Ries 2005), além de contribuírem na construção e sedimentação dos recifes organogênicos (Amorim et al. 2006; DeWreede 2006).

A taxonomia de Udoteaceae tem como base as características vegetativas do talo (Vroom et al. 1998); por exemplo: a presença e nível de calcificação; hábito; estrutura; forma, diâmetro e tipo de ramificação dos sifões, presença de fusões; presença e tipo de apêndices. Isso lhes conferem uma ampla variedade de formas, que são utilizadas para a separação dos táxons (Verbruggen et al. 2009). Devido à amplitude de variações morfológicas e reprodutivas, as relações filogenéticas e evolutivas permaneceram obscuras por muito tempo no grupo. Alguns trabalhos (Hillis et al. 1998; Kooistra 2002; Curtis et al. 2008; Verbruggen et 
al. 2009) vêm contribuindo para um melhor entendimento da filogenia desses grupos, porém a biologia e a ecologia de muitas algas verdes sifonadas ainda são pouco compreendidas (Clifton \& Clifton 1999). Caracteres sutis de reprodução sexuada e assexuada continuam desconhecidos (Rogers 1996) e, por conta disso, muitos táxons podem ter sido identificados de forma equivocada (Vroom et al. 1998).

A microscopia eletrônica de varredura (MEV) tem se mostrado valiosa na taxonomia de macroalgas calcárias, já que a calcificação muitas vezes não possibilita o corte ou dissociação anatômica e, consequentemente, a visualização em microscopia de luz, bem como, a observação de estruturas e ornamentações formadas pela deposição do calcário na superfície dessas algas. Diversos trabalhos permitiram a observação de caracteres úteis à taxonomia de grupos, como nos gêneros de calcárias articuladas vermelhas Tricleocarpa (J.Ellis \& Sol.) Huisman \& Borow. (Afonso-Carrillo et al. 1998), Corallina L. e Haliptilon (Decne.) Lindl. (Garbary \& Johansen 1982), calcárias incrustantes (Costa 2013), e verdes, como Halimeda J.V.Lamour. (Bandeira-Pedrosa et al. 2004a,b). Em Udoteaceae, destacam-se os trabalhos de Littler \& Littler (1990) e Amorim et al. (2006), onde foram observados, em espécies de Udotea sem apêndices nos sifões da lâmina e nas espécies de Penicillus, poros na capa calcária que recobre os filamentos. Os poros só podem ser observados em MEV, pois para a microscopia de luz, essas algas precisam ser descalcificadas, impossibilitando a visualização dessa característica.

O litoral da Bahia, com seus 1.103 km de extensão, é o mais extenso do Brasil e apresenta uma grande diversidade de ambientes litorâneos: praias arenosas, recifes de corais, formações de arenito, costões rochosos e manguezais. Nunes (2005) considera que essa riqueza e diversidade de substratos, além de acidentes geográficos, propiciam uma grande diversificação da flora marinha. Dessa maneira, o litoral da Bahia é uma região prioritária para levantamentos florísticos.

Para o Brasil, a maioria dos estudos abordando a diversidade da família Udoteaceae são trabalhos de cunho florístico, realizados desde o inicio da década de 50 (Barata 2004). No litoral da Bahia, as famílias carecem de estudos aprofundados (Amorim et al. 2006), estando limitados basicamente a inventários florísticos (Martins et al. 1991; Altamirano \& Nunes 1997; Nunes 1998; Nunes et al. 1999; 2001; Marins et al. 2008; Andrade 2012; Costa et al. 2012; Santos et al. 2013). Na Lista de Espécies da Flora do Brasil (Moura 2014), são indicados os gêneros Boodleopsis, Penicillus, Pseudocodium, Rhipidosiphon e Udotea, todos representados na Bahia. Neste estudo, apresentamos o tratamento taxonômico da família Udoteaceae para o litoral do estado da Bahia.

\section{MATERIAL E MÉTODOS}

Estações de coleta. O material estudado é proveniente de coletas no litoral da Bahia entre os anos de 2012 e 2013 ( 22 excursões no mediolitoral e 2 no infralitoral) e de materiais coletados entre os anos de 1960 e 2011 depositados no Herbário Alexandre Leal Costa (ALCB) e no Laboratório de Algas Marinhas (LAMAR), ambos do Instituto de Biologia da Universidade Federal da Bahia. Foram analisados, também, materiais de vários herbários brasileiros: Herbário da Universidade do Estado da Bahia (HUNEB), Herbário Dimitri Sucre Benjamin (RB), Herbário Lauro Pires Xavier (JPB), Herbário do Estado Maria Eneyda P. Kauffmann Fidalgo - Coleção de Algas (SP-Algae), Herbário da Universidade de São Paulo (SPF) e Herbário da Universidade Federal do Rio de Janeiro (RFA). Ao todo, o material examinado compreende coletas de 32 estações no mediolitoral e 34 no infralitoral, em 10 municípios no litoral do estado.

As coletas realizadas no mediolitoral seguiram as técnicas usuais para Ficologia Marinha (Nunes 2010). As praias foram visitadas durante as marés baixas de sizígia, com base na Tábua de Marés do Ministério da Marinha do Brasil. As coletas no infralitoral foram feitas em parceria com a Central de Tratamento de Efluentes Líquidos (CETREL), com o uso de dragas de arrasto tipo Holme e de mordedura tipo Petersen.

Estudos em laboratório. O material coletado foi encaminhado ao Laboratório de Algas Marinhas (LAMAR) do Departamento de Botânica do Instituto de Biologia da Universidade Federal da Bahia e triado a olho nu para separar os espécimes da família Udoteaceae das demais algas. Para a identificação dos táxons em nível infragenérico, observando aspectos da morfologia externa e interna das estruturas vegetativas e reprodutivas, foram consultadas obras comumente utilizadas na Ficologia Marinha para a família (Taylor et al. 1953; Joly 1967; Calderón-Saénz \& Schnetter 1989; Littler \& Littler 1990; Littler \& Littler 2000; Barata 2004; Cassano et al. 2004; Amorim et al. 2006; Collado-Vides et al. 2009; Cabrera \& Alfonso 2010). Fez-se uso, para tanto, de estereomicroscópio Leica ${ }^{\circ}$ Zoom 2000, microscópio óptico Olympus ${ }^{\mathcal{O}}-\mathrm{CX} 22$ e

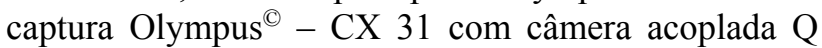
Imaging ${ }^{\odot}$ - Go Series, utilizando o programa $Q$ Imaging $^{\odot}-\mathrm{Q}$ Capture PRO 7, e microscópio eletrônico de varredura $\left(\mathrm{JEOL}^{\circ}\right.$ - JSM 6390 LV). Para as imagens, utilizou-se máquina fotográfica digital Sony ${ }^{\mathcal{O}}$ - Cyber-Shot DSC S2000.

O material herborizado foi separado do que estava em meio líquido (formol a 4\%) com estereomicroscópio e microscópio óptico. O material herborizado foi reidratado em solução contendo água e detergente líquido. Posteriormente, as amostras calcificadas foram descalcificadas por imersão em 
ácido clorídrico $20 \%$ ou ácido nítrico $0,6 \mathrm{M}$, finalizando apenas com o desprendimento total das bolhas de gás carbônico. As lâminas para microscopia foram montadas a partir da dissociação dos filamentos realizada com auxílio de lâminas de barbear e estiletes.

Para microscopia eletrônica de varredura, os espécimes que estavam em meio líquido foram separados dos herborizados, pois as algas em meio líquido tiveram que secar em estufa para serem fragmentadas e posicionadas no stub. As amostras passaram então pelo processo de metalização com ouro (Gold Sputtering of Samples), com atmosfera estabilizada em 50 mTor de Argônio (Denton Vacuum $^{\odot}$ - Desk IV), com tempo de exposição de 5 min, conforme o protocolo padrão utilizado no Centro de Pesquisas Gonçalo Moniz da Fundação Oswaldo Cruz (FIOCRUZ/BA).

A classificação taxonômica segue Wynne (2011), enquanto o basônimo, localidade-tipo e referência da descrição original estão de acordo com Guiry \& Guiry (2014).

\section{TrataMento TAXONÔMICO}

\section{UDOTEACEAE}

Talo ereto ou prostrado, podendo estar calcificado, crescendo isoladamente ou em grupos, fixo ao substrato por apressório bulboso ou pequenos rizoides hialinos. Estipe longo ou curto, cilíndrico ou achatado, liso ou ondulado, podendo apresentar ramificações ou junção entre lâmina e estipe marcada. Lâmina com grande variedade de formas (capitular, flabelar, em forma de taça, entre outras). Talo formado por várias camadas; sifões ramificados, entrelaçados, com diferentes graus de aderência entre os filamentos; apêndices do sifão podendo estar presentes, com forma e ramificação variadas e ápices ramificados, inflados, espinescentes ou truncados.

\section{Chave de identificação}

1. Talo não calcificado, prostrado, não diferenciado em estipe e lâmina, não apresentando apêndices laterais 1. Boodleopsis

1'. Talo calcificado, ereto, diferenciado em estipe e lâmina; estipe com apêndices laterais.

2. Lâmina em forma de pincel

2. Penicillus

2'. Lâmina em forma de taça, funil, leque ou lobo 3. Udotea

\section{Boodleopsis A.Gepp \& E.Gepp}

Talo delicado, não calcificado, prostrado, verde a verde-esbranquiçado, formado por emaranhado de filamentos cenocíticos aderidos ao substrato, fixo ao substrato por pequenos e delicados rizoides hialinos que suportam filamentos rastejantes ramificados di ou tricotomicamente. Filamentos semieretos que emergem dos filamentos rastejantes com ramificação dicotômica, tricotômica, divaricada a irregular, podendo apresentar constrições superficiais a profundas nas ramificações dentro dos sifões de um mesmo indivíduo.

1.1. Boodleopsis pusilla (Collins) W.Taylor, A.B.Joly \& Bernat., Pap. Michigan Acad. Sci. 38: 97. 1953. Figuras 1 e 2 .

Talo verde-escuro a esbranquiçado, que se estende formando massas no substrato; rizoides com filamentos rastejantes dicotômicos. Filamentos semieretos dos filamentos rastejantes com ramificação dicotômica, tricotômica, divaricada, a irregular, com constrição geralmente profunda, variando até superficial. Filamentos rastejantes e semieretos 15-30 $\mu \mathrm{m}$ diâm., cilíndricos, ramificados dicotomicamente, tricotomicamente, ou irregularmente. Filamentos rizoidais delicados, delgados, hialinos, ramificados di ou tricotomicamente. Esporângios nas porções terminais dos filamentos semieretos, formados por um septo que divide a parte reprodutiva da parte vegetativa, porção globosa onde se desenvolvem os esporos e um tubo de descarga por onde os esporos são encaminhados para liberação. Exemplares férteis ocorreram em fase esporofítica.

Encontrada no mediolitoral, sobre substrato rochoso, ou epifitando outras algas, em manguezais, sobre raízes, e em ambientes hipersalinos, como na Lagoa de Araruama, no estado do Rio de Janeiro. Diversos estudos, além de demonstrarem a diversidade de ambientes em que a espécie ocorre, constataram também diferentes intervalos de medidas no diâmetro dos sifões de $B$. pusilla, como 27-45 $\mu \mathrm{m}$ em Taylor et

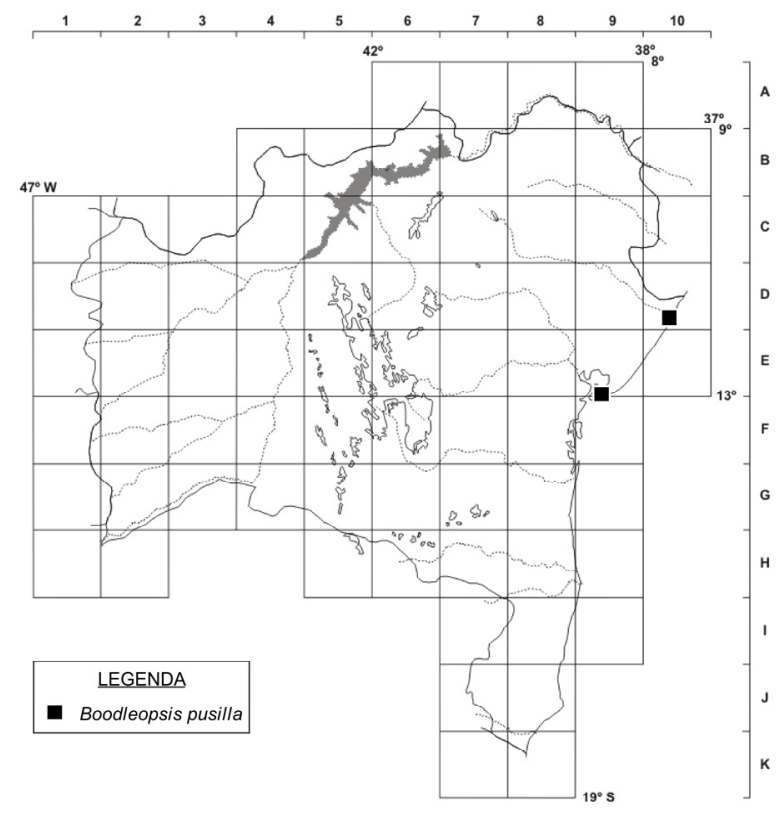

Figura 1. Distribuição de Boodleopsis pusilla no litoral do estado da Bahia. 
al. (1953), 69-72 $\mu \mathrm{m}$ em Yoneshigue-Braga (1970) e 10-20 $\mu \mathrm{m}$ em Calderón-Sáenz \& Schnetter (1989), o que pode estar relacionado ao ambiente em que os espécimes foram coletados. Boodleopsis pusilla apresenta grande plasticidade fenotípica em relação ao padrão de ramificação e à forma e diâmetro dos sifões (Tabela 1). No presente estudo, os espécimes apresentaram o diâmetro dos sifões semelhante ao descrito em trabalhos mais recentes (Calderón-Sáenz \& Schnetter 1989; Reis-Santos 1990), em contraposição aos mais antigos (Taylor et al. 1953; YoneshigueBraga 1970), que apresentaram diâmetros maiores (Tabela 1).

Material examinado - Conde, Barra do Itariri, 5 set. 1997, J.M.C. Nunes (ALCB 32303); Vera Cruz, Praia da Penha, 27 set. 2000, G.M. Amado Filho et al. (RB 375337).

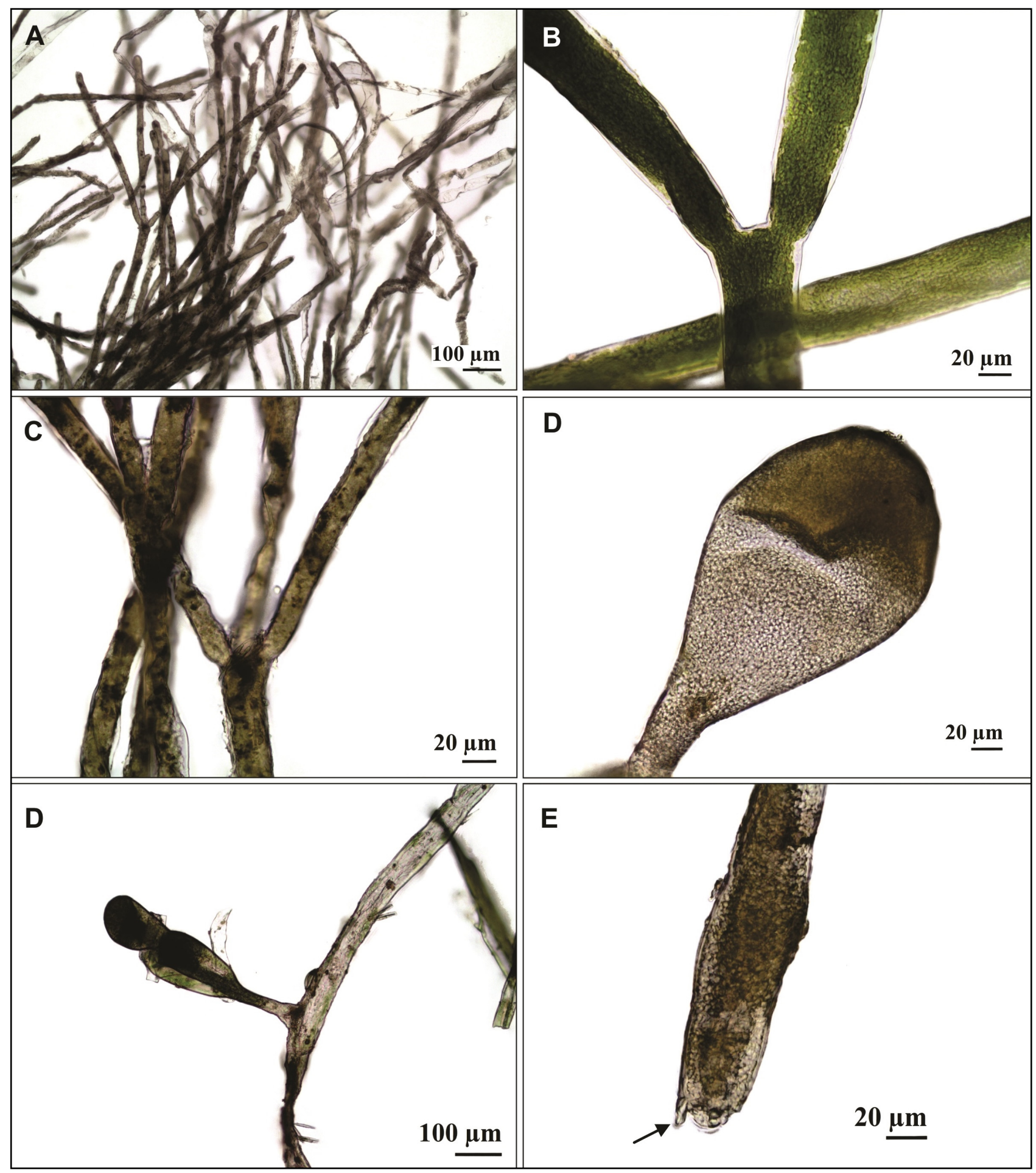

Figura 2. Boodleopsis pusilla: A- aspecto dos sifões entrelaçados; B- detalhe da dicotomia; C- detalhe da tricotomia; D- detalhe do esporângio; E- detalhe do esporângio degenerando-se; F- detalhe do tubo de descarga para saída dos zoósporos (seta). 
Tabela 1. Comparação dos caracteres de Boodleopsis pusilla observados neste e em outros estudos.

\begin{tabular}{|c|c|c|c|c|c|}
\hline & Presente estudo & Taylor et al. (1953) & $\begin{array}{l}\text { Yoneshigue-Braga } \\
\text { (1970) }\end{array}$ & $\begin{array}{l}\text { Calderón-Sáenz \& } \\
\text { Schnetter (1989) }\end{array}$ & Reis-Santos (1990) \\
\hline Hábitat & $\begin{array}{l}\text { Mediolitoral, } \\
\text { manguezal }\end{array}$ & - & Mediolitoral & Mediolitoral & Laguna hipersalina \\
\hline $\begin{array}{l}\text { Diâmetro dos } \\
\text { filamentos } \\
\text { prostrados }\end{array}$ & $15-30 \mu \mathrm{m}$ & - & - & $\begin{array}{l}\text { Menor que os } \\
\text { filamentos } \\
\text { semieretos }\end{array}$ & - \\
\hline $\begin{array}{l}\text { Diâmetro dos } \\
\text { filamentos } \\
\text { semieretos }\end{array}$ & $15-30 \mu \mathrm{m}$ & $27-45 \mu \mathrm{m}$ & $69-72 \mu \mathrm{m}$ & $10-20 \mu \mathrm{m}$ & $16-30 \mu \mathrm{m}$ \\
\hline $\begin{array}{l}\text { Padrão de } \\
\text { ramificação }\end{array}$ & $\begin{array}{l}\text { Dicotômico, } \\
\text { tricotômico ou } \\
\text { irregular }\end{array}$ & $\begin{array}{l}\text { Dicotômico ou } \\
\text { tricotômico }\end{array}$ & $\begin{array}{l}\text { Dicotômico, às vezes } \\
\text { irregular }\end{array}$ & $\begin{array}{l}\text { Divaricado, di ou } \\
\text { tricotômico ou } \\
\text { verticilado }\end{array}$ & $\begin{array}{l}\text { Di ou tricotômico, } \\
\text { ou irregular }\end{array}$ \\
\hline Constrições & $\begin{array}{l}\text { Superficiais ou } \\
\text { profundas acima das } \\
\text { dicotomias }\end{array}$ & $\begin{array}{l}\text { Superficiais ou } \\
\text { profundas acima das } \\
\text { dicotomias e através } \\
\text { dos filamentos }\end{array}$ & $\begin{array}{l}\text { Abaixo das } \\
\text { dicotomias e às } \\
\text { vezes através dos } \\
\text { filamentos }\end{array}$ & $\begin{array}{l}\text { Superficiais ou } \\
\text { profundas acima das } \\
\text { dicotomias }\end{array}$ & $\begin{array}{l}\text { Acima das } \\
\text { dicotomias e às } \\
\text { vezes através dos } \\
\text { filamentos }\end{array}$ \\
\hline
\end{tabular}

\section{Penicillus Lam.}

Talo ereto, calcificado, verde-escuro ou verdeclaro, crescendo isoladamente ou em grupos, fixo ao substrato por apressório bulboso; estipe longo, cilíndrico, frequentemente achatado no ápice, liso, podendo apresentar ramificações. Lâmina em forma de pincel (capítulo), geralmente recobrindo parte do estipe, eventualmente chegando a quase $50 \%$ do tamanho do estipe. Apressório composto por filamentos cilíndricos, hialinos e delgados; estipe dividido em região medular, composto por filamentos cenocíticos centrais, dicotômicos, com apêndices laterais ramificados que recobrem os sifões (região cortical); capítulo composto por numerosos sifões ramificados dicotomicamente, com constrições logo acima das dicotomias; capa calcária que recobre os filamentos capitulares com poros pequenos e numerosos.

\subsection{Penicillus capitatus Lam., Nouv. Ann. Mus. Hist.}

Nat. 20: 294. 1813

Talo moderadamente calcificado, verde a verdeesbranquiçado, em forma de pincel, ereto, até $10 \mathrm{~cm}$ alt., crescendo isoladamente ou em grupos. Apressório bulboso; estipe liso, cilíndrico, raramente ramificado, até $7 \mathrm{~cm}$ compr., 0,2-0,6 cm larg.; capítulo, estreito a esférico, denso ou laxo, até $4,5 \mathrm{~cm}$ compr., $1,6-5 \mathrm{~cm}$ larg. Sifões capitulares 100-300 $\mu \mathrm{m}$ diâm., livres, numerosos, divididos dicotomicamente, constritos acima de todas as dicotomias, com ápices arredondados. Sifões medulares do estipe 99-110 $\mu \mathrm{m}$ diâm., dispostos longitudinalmente de maneira densa, dicotomicamente divididos. Região cortical composta por numerosos apêndices com ápices ramificados ou truncados, fortemente espessados, aderidos entre si.

Encontrada no médio e infralitoral, em substrato arenoso, chegando a profundidades de até $23 \mathrm{~m}$. As formas de Penicillus capitatus apresentam as mesmas características morfológicas, bem como os intervalos de diâmetros, nos sifões e apêndices do estipe. São facilmente reconhecíveis pela sua morfologia externa (Tabela 2), pois as diferenças entre elas são causadas basicamente por variações no hábitat.

\section{Chave de identificação}

1. Capítulo laxo, delicado . 2.1.3. P. capitatus f. laxus

1 '. Capítulo denso, robusto.

2. Capítulo oblongo a esférico; estipe sem ramificação ........ 2.1.1. P. capitatus f. capitatus

2'. Capítulo estreito, oblongo; estipe ramificado ..... 2.1.2. P. capitatus f. elongatus

2.1.1. Penicillus capitatus f. capitatus Lam., Nouv. Ann. Mus. Hist. Nat. 20: 294. 1813

Figuras 3 e 4.

Talo moderadamente calcificado, verde a verdeesbranquiçado, em forma de pincel, ereto, até $10 \mathrm{~cm}$ alt., crescendo isoladamente ou em grupos. Estipe liso, cilíndrico, não ramificado, até $7 \mathrm{~cm}$ compr., $0,3-0,6 \mathrm{~cm}$ larg.; capítulo oblongo a esférico, denso, robusto, até $3,6 \mathrm{~cm}$ compr., $2-5 \mathrm{~cm}$ larg. Sifões capitulares 100 $200 \mu \mathrm{m}$ diâm. Não foram observados exemplares férteis.

Encontrada no médio e infralitoral, em substrato arenoso, chegando a profundidades de cerca de $20 \mathrm{~m}$. Morfológica e anatomicamente, os exemplares analisados estão de acordo com as descrições de Littler \& Littler (2000) e Cabrera \& Alfonso (2010).

Material examinado - Caravelas, Cordão entre Redonda e Siriba, 27 nov. 1984, M.A.O.F. Guerra (RB 228245); Ilha de Siriba, 27 nov. 1984, G.J.P. Mitchell (RFA 1722); Ilha Redonda, jul. 1987, M. Oliveira (SPF 53663); Recife da Lixa, 11 abr. 1964, A.B. Joly et al. (SP-Algae 96210); Santa Bárbara, 26 nov. 1984, M.A.O.F. Guerra (RB 228286); Cairu, Guarapuá, 11 nov. 2000, M.E.C. Ramos (ALCB 53437); Morro de São Paulo, 26 ago. 2000, J.M.C. 


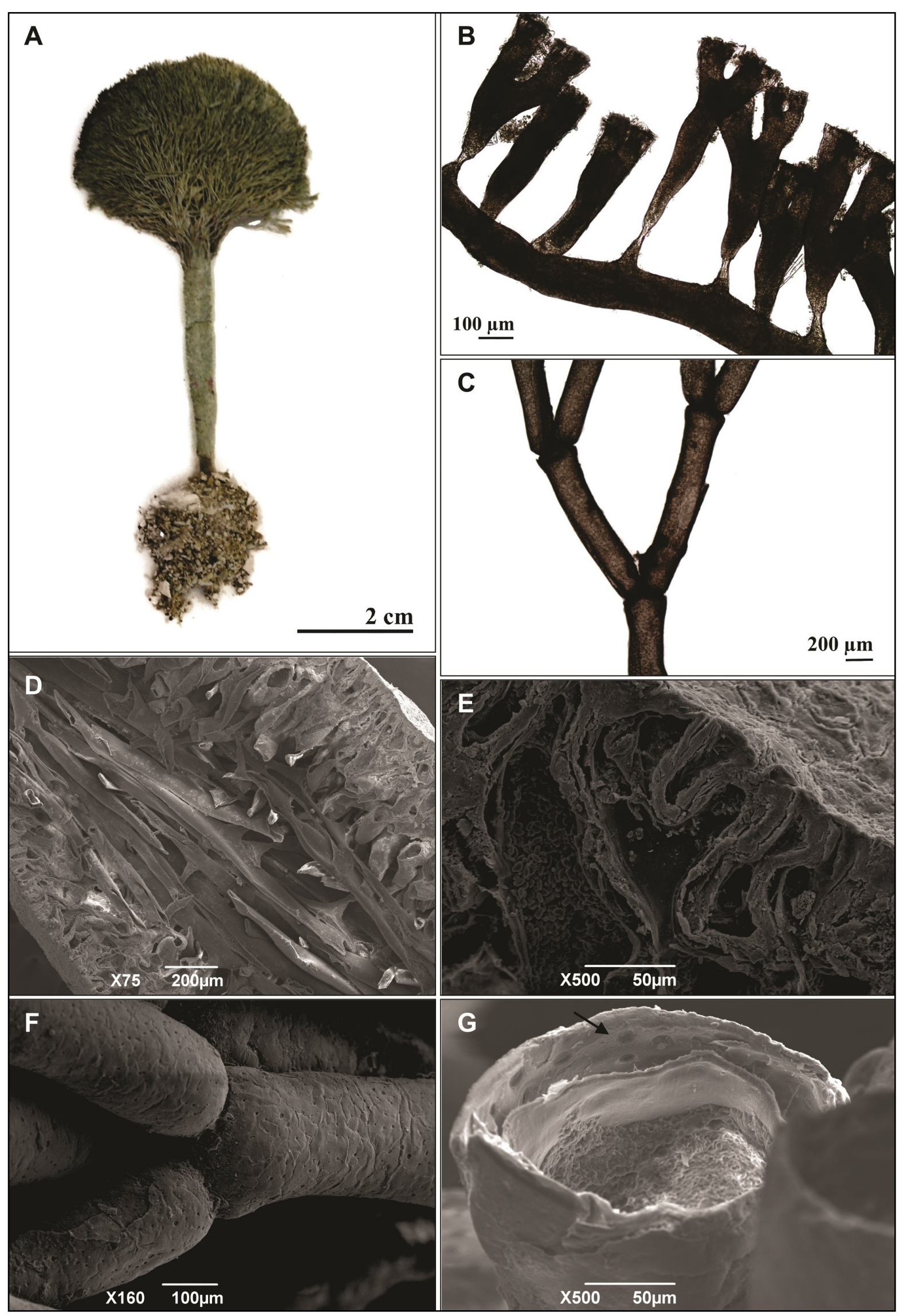

Figura 3. Penicillus capitatus f. capitatus: A- aspecto geral; B- detalhe de um sifão do estipe e apêndices; C- detalhe de um sifão do capítulo e dicotomias; D- corte transversal do estipe evidenciando sifões longitudinais e apêndices; E- detalhe de um apêndice de um sifão do estipe; F- detalhe da dicotomia do sifão do capítulo; G- detalhe da capa calcária de um sifão do capítulo e poros (seta) (D-G- Microscopia Eletrônica de Varredura). 
Tabela 2. Comparação dos caracteres morfológicos e anatômicos entre as formas de Penicillus capitatus.

\begin{tabular}{|c|c|c|c|}
\hline & P. capitatus f. capitatus & P. capitatus f. elongatus & P. capitatus f. laxus \\
\hline Altura & Até $10 \mathrm{~cm}$ & Até $10 \mathrm{~cm}$ & Até $7 \mathrm{~cm}$ \\
\hline Dimensões do estipe & Até $7 \mathrm{~cm}$ compr. e $6 \mathrm{~mm}$ larg. & Até $6 \mathrm{~cm}$ compr. e $4 \mathrm{~mm}$ larg. & Até $3 \mathrm{~cm}$ compr. e $2 \mathrm{~mm}$ larg. \\
\hline Forma do estipe & Cilíndrico & Cilíndrico & Cilíndrico \\
\hline Ramificações do estipe & Ausentes & Presentes & Ausentes \\
\hline Dimensões do capítulo & Até $3,6 \mathrm{~cm}$ compr. $\times 5 \mathrm{~cm}$ larg. & Até $4,5 \mathrm{~cm}$ compr. $\times 2 \mathrm{~cm}$ larg. & Até $4,5 \mathrm{~cm}$ compr. $\times 3,5 \mathrm{~cm}$ larg. \\
\hline Forma do capítulo & Oblongo a esférico, denso & Estreito a oblongo, denso & Estreito, laxo \\
\hline Diâmetro dos sifões do estipe & $99-110 \mu \mathrm{m}$ & Até $300 \mu \mathrm{m}$ & $145-175 \mu \mathrm{m}$ \\
\hline $\begin{array}{l}\text { Forma dos apêndices do } \\
\text { estipe }\end{array}$ & $\begin{array}{l}\text { Ápices ramificados ou truncados } \\
\text { e fortemente espessados }\end{array}$ & $\begin{array}{l}\text { Ápices ramificados ou truncados } \\
\text { e fortemente espessados }\end{array}$ & $\begin{array}{l}\text { Ápices ramificados ou truncados } \\
\text { e fortemente espessados }\end{array}$ \\
\hline $\begin{array}{l}\text { Diâmetro dos sifões do } \\
\text { capítulo }\end{array}$ & $100-200 \mu \mathrm{m}$ & $150-300 \mu \mathrm{m}$ & $145-175 \mu \mathrm{m}$ \\
\hline
\end{tabular}

Nunes \& A. Minervino Netto (ALCB 49457); Nova Viçosa, 18 abr. 1988, G.J.P. Mitchell (RFA 4459); Arrecifes, 15 dez. 1985, G.J.P. Mitchell (RFA 2056); Ilha de Coroa Vermelha, 26 jan. 1988, G.J.P. Mitchell (RFA 4492); 24 nov. 1998, A.E.S. Oliveira (RB 353632); Prado, Distrito de Cumuruxatiba, 10 mar. 2001, J.M.C. Nunes \& G.M. Lyra (ALCB 68419); Ponta do Moreira, 5 jun. 2001, J.M.C. Nunes et al. (ALCB 103537); Salvador, Praia de Amaralina, 15 fev. 1982, E. Nonato (SPF 694); Santa Cruz Cabrália, Praia de Arakakaí, 9 mar. 2001, J.M.C. Nunes \& G.M. Lyra (ALCB 68457); Vera Cruz, Barra Grande, 20 dez. 1990, A.P. Nunes (ALCB 17197); Praia da Penha, 28 ago. 1995, J.M.C. Nunes \& M. Altamirano (ALCB 22235); 16 out. 2012, G.N. Santos et al. (ALCB 103697); Praia de Mar Grande, 17 abr. 2000, J.M.C. Nunes (ALCB 103696); Praia de Pedrão, 18 set. 1982, M.L. Christoffersen (RFA 1574).

\subsubsection{Penicillus capitatus f. elongatus (Decne.)}

A.Gepp \& E.Gepp, Siboga-Expeditie Monographie LXII: 83. 1911. Penicillus elongatus Decne., Ann. Sci. Nat., Bot. 18: 96. 1842.

Figuras 4 e 5 .

Talo moderadamente calcificado, verde a verdeamarronzado, ereto, até $10 \mathrm{~cm}$ alt., crescendo isoladamente ou em tufos. Estipe liso, cilíndrico, podendo ser ramificado, até $6 \mathrm{~cm}$ compr., $0,4 \mathrm{~cm}$ larg., penetrando até quase a metade no capítulo; capítulo estreito e oblongo, denso, robusto, até $4,5 \mathrm{~cm}$ compr., $1,6-2 \mathrm{~cm}$ larg. Sifões do capítulo espessos, até $300 \mu \mathrm{m}$ diâm. Não foram observados exemplares férteis.

Encontrada no mediolitoral, em substrato arenoso. De acordo com Gepp \& Gepp (1911), Penicillus capitatus f. elongatus pode ser diferenciado das demais formas pelo estipe, que penetra profundamente no capítulo, e possui filamentos de diâmetros maiores. Nesta forma, observou-se que a ramificação lateral do estipe dá origem a um novo capítulo, que pode se entrelaçar ao capítulo da planta-mãe, concordando com Cabrera \& Alfonso (2010). Essa é a primeira citação dessa forma para o litoral brasileiro.
Material examinado - Prado, Curumuxatiba, 4 jun. 2001, J.M.C. Nunes (ALCB 103478).

\subsubsection{Penicillus capitatus f. laxus Boergesen, Dansk} Bot. Ark. 1(4): 98.1913

Figuras 4 e 5.

Talo moderadamente calcificado, esbranquiçado, em forma de pincel, ereto, até $7 \mathrm{~cm}$ alt. Estipe liso, cilíndrico, não ramificado, até $3 \mathrm{~cm}$ compr., ca. $2 \mathrm{~mm}$ larg.; capítulo laxo, delicado, até 4,5 cm compr., 3,5 $\mathrm{cm}$ larg. Sifões do capítulo delgados, 145-175 $\mu \mathrm{m}$ diâm., laxos. Não foram observados exemplares férteis.

Encontrada no infralitoral, em substrato arenoso, alcançando profundidades de até $23 \mathrm{~m}$. Esta forma difere das demais por apresentar filamentos capitulares

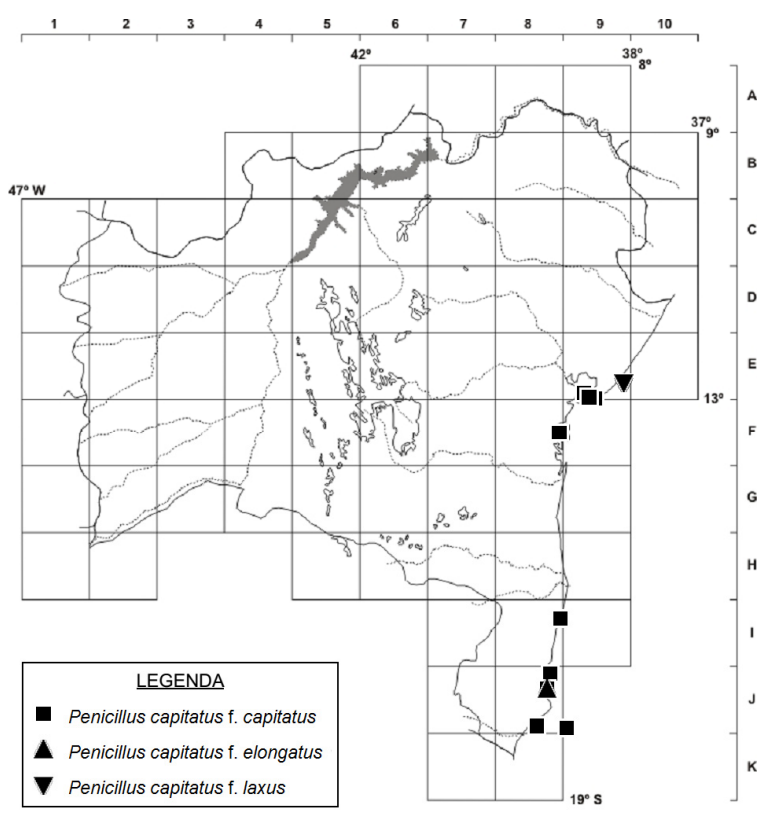

Figura 4. Distribuição das formas de Penicillus capitatus no litoral do estado da Bahia. 


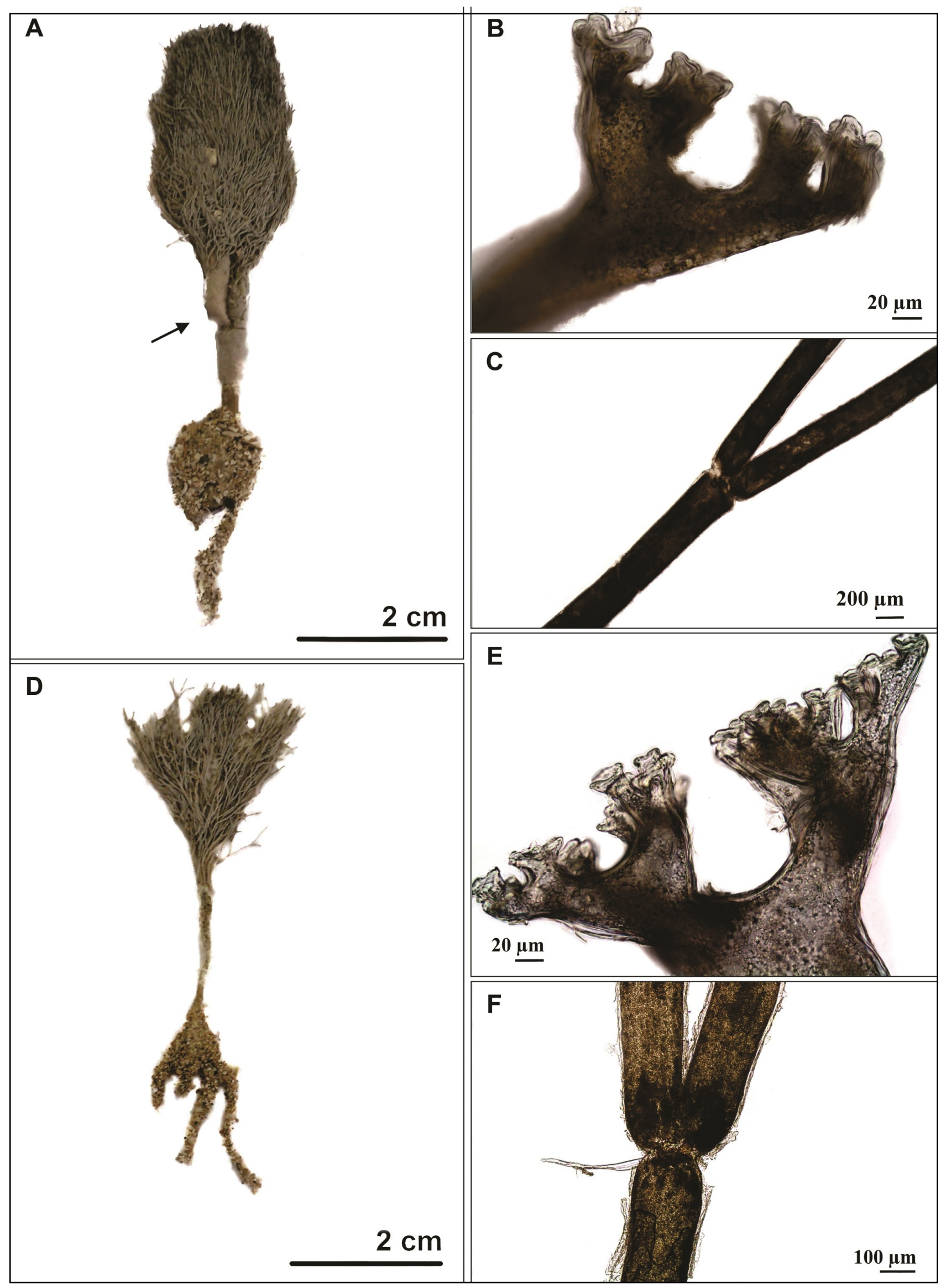

Figura 5. A-C. Penicillus capitatus f. elongatus: A- aspecto geral, com detalhe para a ramificação lateral do estipe (seta); B- detalhe do apêndice do sifão do estipe; C- detalhe da dicotomia do sifão do capítulo. D-F. Penicillus capitatus f. laxus: D-aspecto geral; E- detalhe do apêndice do sifão do estipe; F- detalhe da dicotomia do sifão do capítulo. 
com diâmetros menores e em pouca quantidade, conferindo um aspecto laxo. Os exemplares analisados estão de acordo com a descrição de Cabrera \& Alfonso (2010). Está é a primeira citação para a costa brasileira.

Material examinado - Camaçari, \#A4, 1244'12,03”S, 3805'12,53”W, jan. 2009, CETREL (ALCB 99825); jan. 2009, CETREL (ALCB 98180); jan. 2010, CETREL (ALCB 98178); jan. 2012, CETREL (ALCB 110232).

\section{Udotea J.V.Lamour.}

Talo calcificado, verde com tons castanhos, amarelos e cinzas, podendo passar a esbranquiçados quando secos, ereto, crescendo isoladamente ou em grupos, fixo ao substrato por apressório bulboso; estipe cilíndrico a levemente achatado, liso, eventualmente com uma marca onde a lâmina começa; lâmina frequentemente maior que $50 \%$ do talo, em forma de taça, funil, leque ou lobo. Sifões do talo ramificados e emaranhados, dicotômicos, constritos ou não acima das dicotomias. Filamentos rizoidais delgados, hialinos, bastante ramificados, aglomerados ao substrato garantindo fixação; região medular do estipe composta por filamentos cenocíticos centrais dicotômicos e numerosos apêndices laterais ramificados que recobrem os sifões formando a região cortical. Sifões das lâminas dicotômicos, constritos nas dicotomias, apêndices laterais presentes ou não.

A partir das caracteristicas morfoanatômicas das lâminas no gênero Udotea, é possivel agrupar suas espécies e táxons infraespecíficos de acordo com a presença/ausência de apêndices sifonais. Udotea abbottiorum e $U$. cyathiformis não apresentam apêndices enquanto $U$. dixonii e $U$. flabellum apresentam. O primeiro grupo apresenta lâminas fibrosa e mais frágeis, enquanto o segundo grupo possui lâmina fortemente consolidada e coriácea. Essas caraterísticas parecerem ter valor taxonômico, pois estudos filogenéticos (e.g., Kooistra 2002; Verbruggen et al. 2009) têm demonstrado que Udotea não é um gênero monofilético, e que as espécies sem apêndices nos sifões da lâmina estão mais relacionadas ao gênero Penicillus. Além disso, a forma e diâmetro dos sifões e a presença/ausência e forma dos apêndices laterais dos sifões são caracteres taxonômicos valiosos para a identificação das espécies (Tabela 3), concordando com Littler \& Littler (1990) e Collado-Vides et al. (2009).

\section{Chave de identificação}

1. Sifões da lâmina com apêndices laterais.

2. Plantas isoladas ou em grupos de 2 a 5 indivíduos; lâmina lobada; apêndices sifonais numerosos, aos pares................... 3.3. U. dixonii

2'. Plantas isoladas; lâmina inteira; apêndices sifonais pouco numerosos, alternados 3.4. U. flabellum

1'. Sifões da lâmina sem apêndices laterais.

3. Lâmina em forma de taça ou funil.
4. Lâmina 1-2 mm espessura; sifões da lâmina

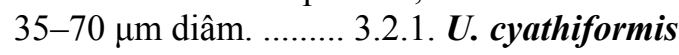
var. cyathiformis f. cyathiformis

4'. Lâmina 2-3 mm espessura, sifões da lâmina medindo 60-80 $\mu \mathrm{m}$ diâm.

var. cyathiformis f. sublittoralis

3.2.2. U. cyathiformis

3'. Lâmina em forma de leque.

5. Estipe cilíndrico; sifões da lâmina $60-80 \mu \mathrm{m}$ diâm. 3.2.3. U. cyathiformis var. flabellifolia

5'. Estipe dividido em duas seções distintas, superior flabeliforme e inferior cilíndrica; sifões da lâmina 90-110 $\mu \mathrm{m}$ diâm.

3.1. U. abbottiorum

\subsection{Udotea abbottiorum D.S.Littler \& M.M.Littler,} Phycologia 29(2): 211. 1990.

Figuras 6 e 7.

Talo moderadamente calcificado, verde a verdeamarronzado, até $8 \mathrm{~cm}$ alt. Apressório bulboso; estipe cilíndrico, 1,5-2,5 cm compr., 1-3 mm diâm., dividido numa seção inferior cilíndrica e numa superior flabeliforme; lâmina flabeliforme, delicada, fibrosa, sem zonação, frequentemente rasgada, 3,5-6,5 cm compr., 2-4,5 cm larg., 1-2 mm espessura. Sifões laminares 90-110 $\mu \mathrm{m}$ diâm., subparalelos, igualmente constritos acima das dicotomias, sem apêndices laterais. Capa calcária que recobre os filamentos laminares com poros pequenos e numerosos e projeções semelhantes a soldaduras que unem os sifões. Sifões medulares do estipe 70-100 $\mu \mathrm{m}$ diâm. Apêndices laterais da porção superior com ápices inflados e da porção inferior com ápices abruptamente truncados. Não foram observados exemplares férteis.

Encontrada no infralitoral, em cascalho biodetrítico, em profundidades entre 20 e $60 \mathrm{~m}$. Os exemplares analisados estão de acordo com as descrições de Littler \& Littler $(1990,2000)$ e Collado-Vides et al. (2009) em relação ao hábito, morfologia externa e anatomia.

Material examinado - Banco Royal Charlotte, Estação 438, 16 $24^{\circ}$ 'S, 38²6'W, 14 jun. 1999, Projeto Revizee (RFA 28108); Cordilheira Marinha Ferraz, Estação 075, 1606'08"S, 3202'06”W, 4 jun. 1999, Projeto Revizee (RFA 28110); Ilhéus, Estação 04 14\%48'30"S, 3855'00'W, 1 jul. 2001, Projeto Revizee (RFA 28111).

\subsection{Udotea cyathiformis Decne., Ann. Sci. Nat., Bot.} 18: 96.1842.

Talo calcificado, verde-claro a verde-escuro, esbranquiçado ou amarelado quando seco, ereto, até 5 $\mathrm{cm}$ alt., crescendo isoladamente ou em grupos. Apressório bulboso; estipe cilíndrico, liso, não ramificado, 0,3-2 cm compr., 0,1-0,3 cm diâm., junção entre estipe e lâmina com marca nítida; lâmina em forma de leque, taça ou funil, delicada porém resistente, levemente zonada, fibrosa, frequentemente rasgada, 1-4 cm compr., 1,5-4 cm larg., 1-3 mm espessura. Sifões da lâmina 35-80 $\mu \mathrm{m}$ diâm., paralelos a entrelaçados, igualmente constritos acima das 
Tabela 3. Comparação dos caracteres morfológicos e anatômicos entre os representantes do gênero Udotea

\begin{tabular}{|c|c|c|c|c|c|c|}
\hline & U. abbottiorum & $\begin{array}{l}\text { U. cyathiformis } \\
\text { f. cyathiformis }\end{array}$ & $\begin{array}{l}\text { U. cyathiformis } \\
\text { f. sublittoralis }\end{array}$ & $\begin{array}{l}\text { U. cyathiformis } \\
\text { var. flabellifolia }\end{array}$ & U. dixonii & U. flabellum \\
\hline Crescimento & Crescendo isoladamente & $\begin{array}{l}\text { Crescendo isoladamente ou } \\
\text { em grupos }\end{array}$ & $\begin{array}{l}\text { Crescendo isoladamente ou } \\
\text { em grupos }\end{array}$ & Crescendo isoladamente & $\begin{array}{l}\text { Crescendo isoladamente ou } \\
\text { em grupos }\end{array}$ & Crescendo isoladamente \\
\hline Altura & Até $8 \mathrm{~cm}$ & Até $4 \mathrm{~cm}$ & Até $5 \mathrm{~cm}$ & Até $5 \mathrm{~cm}$ & Até $17 \mathrm{~cm}$ & Até $12 \mathrm{~cm}$ \\
\hline Dimensões do estipe & $\begin{array}{l}1,5-2,5 \mathrm{~cm} \text { compr. } \\
1-3 \mathrm{~mm} \text { diâm. }\end{array}$ & $\begin{array}{l}0,4-2 \mathrm{~cm} \text { compr. } \\
1-3 \mathrm{~mm} \text { diâm. }\end{array}$ & $\begin{array}{l}0,3-1,5 \mathrm{~cm} \text { compr. } \\
1-3 \mathrm{~mm} \text { diâm. }\end{array}$ & $\begin{array}{l}\text { Até } 1,5 \mathrm{~cm} \text { compr. } \\
1 \mathrm{~mm} \text { diâm. }\end{array}$ & $\begin{array}{l}0,4-3 \mathrm{~cm} \text { compr. } \\
0,5-2 \mathrm{~mm} \text { diâm. }\end{array}$ & $\begin{array}{l}0,5-2 \mathrm{~cm} \text { compr. } \\
0,5-5 \mathrm{~mm} \text { diâm. }\end{array}$ \\
\hline Forma do estipe & $\begin{array}{l}\text { Duas seções, superior } \\
\text { flabeliforme e inferior } \\
\text { cilíndrica }\end{array}$ & $\begin{array}{l}\text { Cilíndrico, demarcado onde a } \\
\text { lâmina começa }\end{array}$ & $\begin{array}{l}\text { Cilíndrico, demarcado onde } \\
\text { a lâmina começa }\end{array}$ & $\begin{array}{l}\text { Cilíndrico, demarcado onde } \\
\text { a lâmina começa }\end{array}$ & Cilíndrico & Cilíndrico \\
\hline Dimensões da lâmina & $\begin{array}{l}3,5-6,5 \mathrm{~cm} \text { compr. } \\
2,0-4,5 \mathrm{~cm} \text { larg. } \\
1-2 \mathrm{~mm} \text { espessura }\end{array}$ & $\begin{array}{l}1-3,9 \mathrm{~cm} \text { compr. } \\
1,5-4 \mathrm{~cm} \text { larg. } \\
1-2 \mathrm{~mm} \text { espessura }\end{array}$ & $\begin{array}{l}1,5 \text { e } 4 \mathrm{~cm} \text { compr. } \\
1,7-4 \mathrm{~cm} \text { larg. } \\
2-3 \mathrm{~mm} \text { espessura }\end{array}$ & $\begin{array}{l}\text { Até } 3,8 \mathrm{~cm} \text { compr. } \\
2-4 \mathrm{~cm} \text { larg. } \\
1-2 \mathrm{~mm} \text { espessura }\end{array}$ & $\begin{array}{l}3,8-14 \mathrm{~cm} \text { compr. } \\
2,5-5 \mathrm{~cm} \text { larg. } \\
2-8 \mathrm{~mm} \text { espessura }\end{array}$ & $\begin{array}{l}\text { Até } 10 \mathrm{~cm} \text { compr. } \\
3-12 \mathrm{~cm} \text { larg. } \\
1-2 \mathrm{~mm} \text { espessura }\end{array}$ \\
\hline $\begin{array}{l}\text { Forma e textura da } \\
\text { lâmina }\end{array}$ & $\begin{array}{l}\text { Forma de leque, textura } \\
\text { fibrosa, zonação ausente }\end{array}$ & $\begin{array}{l}\text { Forma de taça ou funil, } \\
\text { textura fibrosa, zonação } \\
\text { definida ou indefinida }\end{array}$ & $\begin{array}{l}\text { Forma de funil, textura } \\
\text { fibrosa, zonação definida } \\
\text { ou indefinida }\end{array}$ & $\begin{array}{l}\text { Forma de leque, textura } \\
\text { fibrosa, zonação definida ou } \\
\text { indefinida }\end{array}$ & $\begin{array}{l}\text { Lobada, com } \\
\text { prolongamentos estreitos, } \\
\text { textura coriácea, zonada }\end{array}$ & $\begin{array}{l}\text { Forma de leque, textura } \\
\text { áspera, zonação presente } \\
\text { ou não }\end{array}$ \\
\hline $\begin{array}{l}\text { Diâmetro dos sifões do } \\
\text { estipe }\end{array}$ & $70-100 \mu \mathrm{m}$ & $60-100 \mu \mathrm{m}$ & $60-100 \mu \mathrm{m}$ & $60-100 \mu \mathrm{m}$ & $40-56 \mu \mathrm{m}$ & $20-60 \mu \mathrm{m}$ \\
\hline $\begin{array}{l}\text { Apêndices dos sifões do } \\
\text { estipe }\end{array}$ & $\begin{array}{l}\text { Superiores inchados, } \\
\text { inferiores com ápices } \\
\text { truncados }\end{array}$ & $\begin{array}{l}\text { Ramificados, com ápices } \\
\text { dilatados ou achatados }\end{array}$ & $\begin{array}{l}\text { Ramificados, com ápices } \\
\text { dilatados ou achatados }\end{array}$ & $\begin{array}{l}\text { Ramificados, com ápices } \\
\text { dilatados ou achatados }\end{array}$ & $\begin{array}{l}\text { Numerosos, com ápices } \\
\text { truncados }\end{array}$ & $\begin{array}{l}\text { Numerosos, com ápices } \\
\text { truncados }\end{array}$ \\
\hline $\begin{array}{l}\text { Diâmetro dos sifões da } \\
\text { lâmina }\end{array}$ & $90-110 \mu \mathrm{m}$ & $35-70 \mu \mathrm{m}$ & $60-80 \mu \mathrm{m}$ & $60-80 \mu \mathrm{m}$ & $20-35 \mu \mathrm{m}$ & $28-44 \mu \mathrm{m}$ \\
\hline $\begin{array}{l}\text { Apêndices dos sifões da } \\
\text { lâmina }\end{array}$ & Não apresenta & Não apresenta & Não apresenta & Não apresenta & $\begin{array}{l}\text { Numerosos, com ápices } \\
\text { arredondados }\end{array}$ & $\begin{array}{l}\text { Escassos, com ápices } \\
\text { achatados }\end{array}$ \\
\hline
\end{tabular}




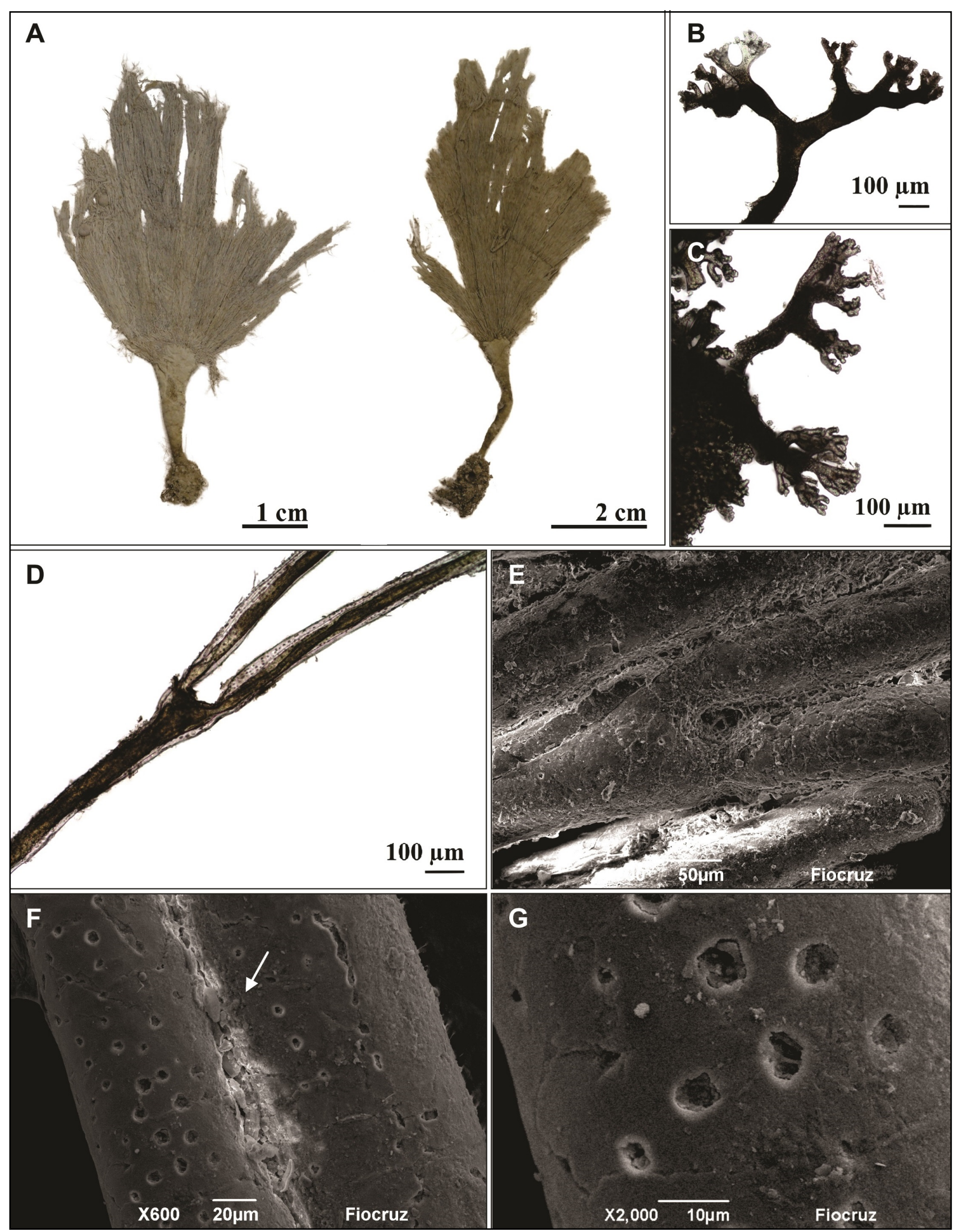

Figura 6. Udotea abbottiorum: A- aspecto geral; B- apêndice lateral da porção inferior do estipe; C- apêndice lateral da porção superior do estipe; D- dicotomia de um sifão da lâmina; E- dicotomia de um sifão da lâmina; F- detalhe da soldagem formada pelo carbonato de cálcio entre os sifões da lâmina (seta); G- detalhe dos numerosos poros de um sifão da lâmina (E-G- Microscopia Eletrônica de Varredura).

dicotomias, sem apêndices laterais. Capa calcária que recobre os filamentos laminares com poros pequenos e numerosos, permitindo que os sifões entrem em contato diretamente com o ambiente, e projeções 


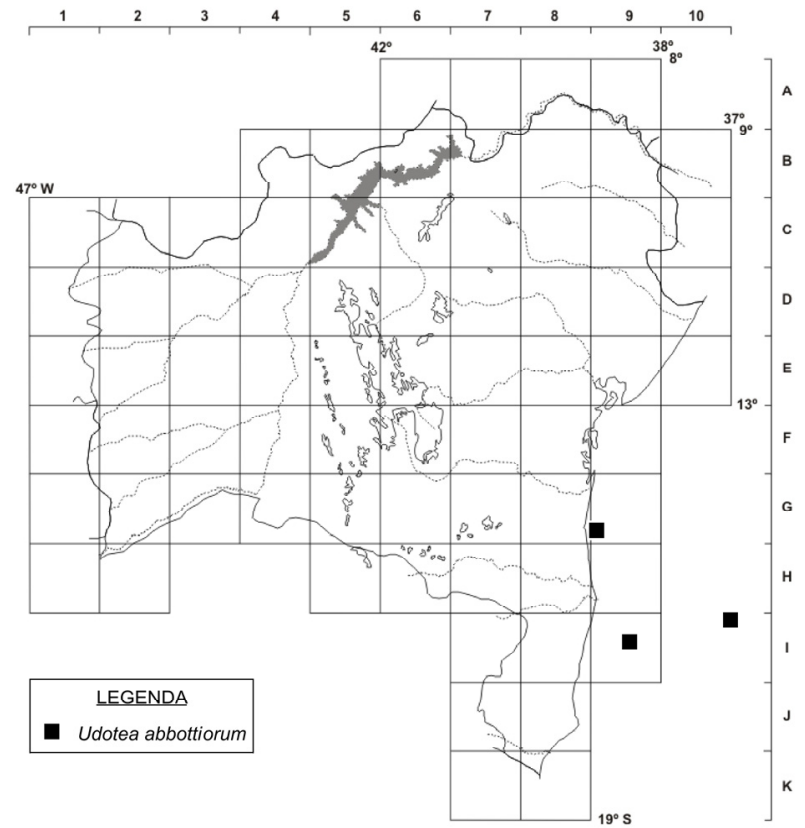

Figura 7. Mapa de distribuição de Udotea abbottiorum no litoral do estado da Bahia.

semelhantes a soldaduras que mantêm os sifões agregados entre si. Sifões da região medular do estipe 60-100 $\mu \mathrm{m}$ diâm., dicotômicos e apêndices laterais repetidamente ramificados, com ápices dilatados ou achatados que recobrem os filamentos centrais formando a região cortical. Não foram observados exemplares férteis.

Encontrada no médio e infralitoral, em substrato arenoso ou biodetrítico, chegando a profundidades de até $45 \mathrm{~m}$. As variedades e formas de Udotea cyathiformis apresentam as mesmas características morfológicas, bem como os intervalos de diâmetros, nos sifões e apêndices do estipe, mas são facilmente reconhecíveis pela morfologia externa da lâmina e pelo diâmetro dos sifões laminares.

3.2.1. Udotea cyathiformis var. cyathiformis $\mathrm{f}$. cyathiformis Decne., Ann. Sci. Nat., Bot. 18: 96. 1842.

Figuras 8 e 9.

Talo calcificado, verde a verde-esbranquiçado ou amarelado, ereto, até $4 \mathrm{~cm}$ alt., crescendo isoladamente ou em grupos. Estipe cilíndrico, liso, não ramificado, 0,4-2 cm compr., 0,1-0,3 cm diâm.; lâmina em forma de taça ou funil, delicada, levemente zonada, fibrosa, frequentemente rasgada, $1-3,9 \mathrm{~cm}$ compr., $1,5-4 \mathrm{~cm}$ larg., 1-2 mm espessura. Sifões da lâmina 35-70 $\mu \mathrm{m}$ diâm. Não foram observados exemplares férteis.

Encontrada no mediolitoral, na região frontal do recife ou em poças, em substrato arenoso, e no infralitoral, em substrato arenoso ou biodetrítico, não ultrapassando a profundidade de $10 \mathrm{~m}$. Anatomicamente, os exemplares analisados estão de acordo com as descrições em Littler \& Littler (1990, 2000), porém relativamente menores.
Material examinado - Caravelas, Santa Bárbara, 26 nov. 1984, M.A.O.F. Guerra (RB 228285); Camaçari, \#A6, 1244'58"S, 38 04'04"W, 19 fev. 2002, CETREL (ALCB 60730); \#E4 124'31,05”S, 38 07'58,24”W, fev. 2011, CETREL (ALCB 100490); Nova Viçosa, Ilha de Coroa Vermelha, 25 ago. 1988, G.J.P. Mitchell (RFA 6661); 3 jun. 2012, T.A. Caires (ALCB 103472); Porto Seguro, Mucugê, 12 mar. 2001, J.M.C. Nunes et al. (ALCB 52989, HUNEB 8353); 5 jun. 2012 T.A. Caires (ALCB 103470); Salvador, Praia de Amaralina, 11 abr. 1952, E. Nonato (SPF 4414); Praia de Itapuã, 21 jul. 2007, G.M. Amado-Filho \& R. Bahia (ALCB 90638); Santa Cruz Cabrália, Recife da Lixa, 11 jun. 1964, A.B. Joly et al. (ALCB 48233; SP-Algae 96119); Vera Cruz, Barra do Pote, 31 jul. 1997, J.M.C. Nunes (ALCB 49473); Praia de Mar Grande, 6 out. 1964, A.B. Joly \& Y. Ugadim (ALCB 48223); Praia da Penha, 9 out. 2004, G.M. Amado Filho (RB 464068); 16 out. 2012, G.N. Santos et al. (ALCB 103500).

\subsubsection{Udotea cyathiformis var. cyathiformis $\mathrm{f}$.} sublittoralis (W.R.Taylor) D.S.Littler \& M.M.Littler, Phycologia 29(2): 216. 1990. Udotea sublittoralis W.R.Taylor, Publ. Carnegie Inst. Wash. 1: 219. 1928.

Figuras 9 e 10.

Talo calcificado, verde-claro a esbranquiçado, em forma de funil, até $5 \mathrm{~cm}$ alt., crescendo isoladamente ou em grupos. Estipe cilíndrico, liso, não ramificado, 0,3-1,5 cm compr., $1-3 \mathrm{~mm}$ diâm.; lâmina em forma de funil, frequentemente rasgada, resistente, apresentando fibras espessas e zonação fraca, $1,5-4 \mathrm{~cm}$ compr., 1,7-4 cm larg., 2-3 mm espessura. Sifões da lâmina $\quad 60-80 \mu \mathrm{m}$ diâm. Não foram observados exemplares férteis.

Encontrada predominantemente no infralitoral, em cascalho biodetrítico, alcançando profundidades de até $45 \mathrm{~m}$. Udotea cyathiformis var. cyathiformis $\mathrm{f}$. sublittoralis assemelha-se bastante à forma-tipo, mas se diferencia pela lâmina mais espessa e com sifões de diâmetro maior (Littler \& Littler 1990, 2000).

Material selecionado - Baixo Sul, Estação 02, 1336'23"S, 38 53'18,1'W, 7 jan. 2004, ENSR (ALCB 61087); Estação 06,

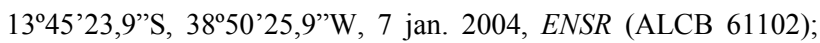

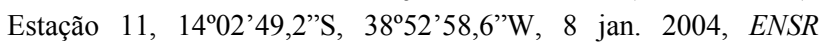
(ALCB 61080); Camaçari, \#A4, 1244'12,03”'S, 38 05'12,53”'W, jan. 2013, CETREL (ALCB 107098); Arembepe, 17 maio 1993, Cepemar (ALCB 22155); Salvador, Estação OC-12, 1258'33,4"S, 38²2'16,6”', 17 jan. 2003, EMBASA (ALCB 60708); Vera Cruz, Praia da Penha, 24 abr. 2001, G.M. Amado-Filho (ALCB 90788).

\subsubsection{Udotea cyathiformis var. flabellifolia D.S.Littler}

\& M.M.Littler, Phycologia 29(2): 220. 1990.

Figuras 9 e 11.

Talo calcificado, verde-claro ou verde-escuro a esbranquiçado quando seco, ereto, solitário, até $5 \mathrm{~cm}$ alt. Estipe cilíndrico, liso, não ramificado, até $1,5 \mathrm{~cm}$ compr., ca. $1 \mathrm{~mm}$ larg.; lâmina flabeliforme, fibrosa, frequentemente rasgada, ocupando a maior parte do corpo do talo, até 3,8 cm compr., 2-4 cm larg., com zonação definida ou não. Sifões da lâmina $60-80 \mu \mathrm{m}$ diâm. Não foram observados exemplares férteis. 


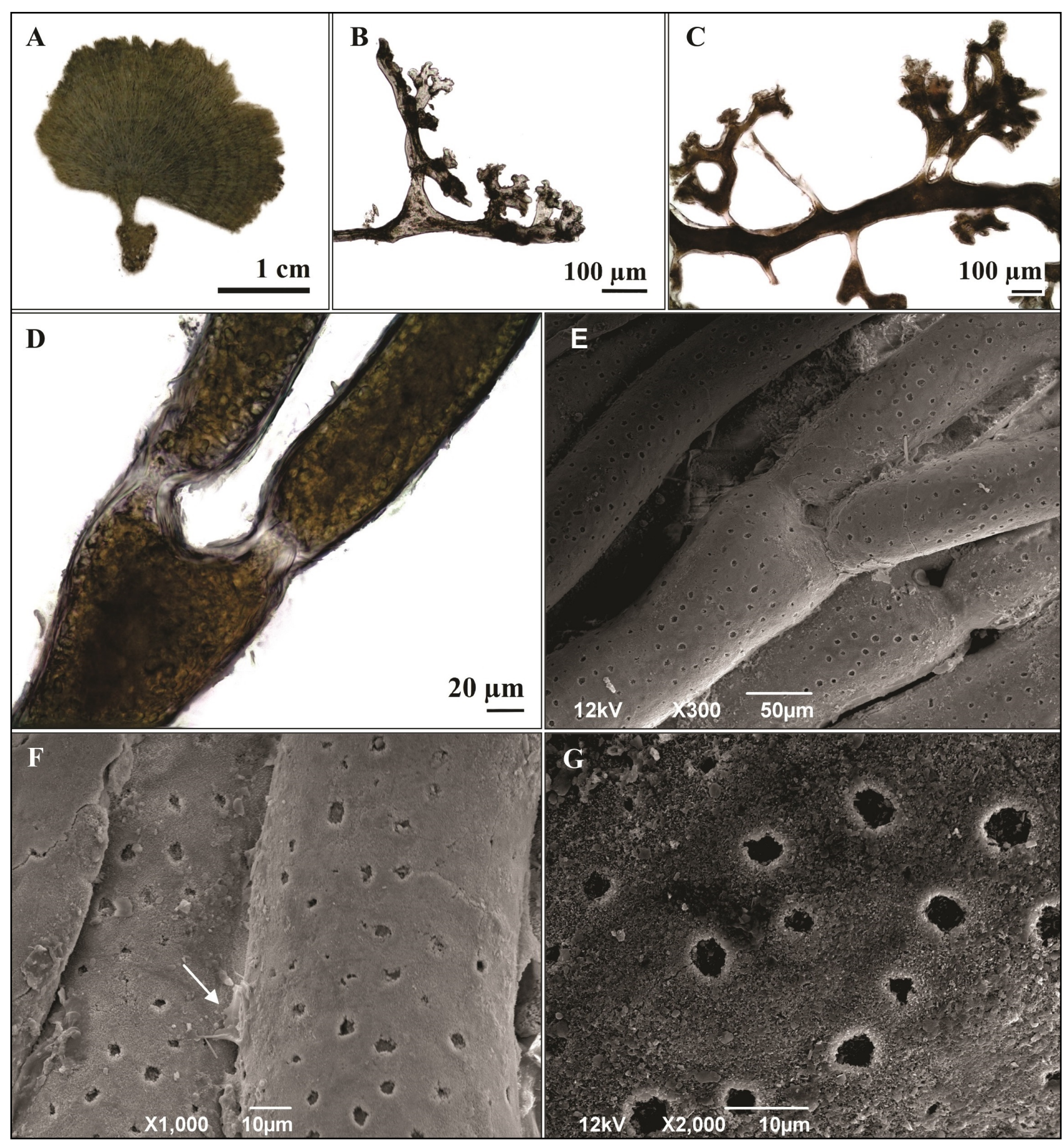

Figura 8. Udotea cyathiformis var. cyathiformis f. cyathiformis: A- aspecto geral; B- detalhe do apêndice lateral do estipe; C- sifão do estipe; D- sifão da lâmina e dicotomia; E- dicotomia do sifão da lâmina; F- detalhe da soldadura formada pelo carbonato de cálcio entre os sifões da lâmina (seta); G- detalhe dos numerosos poros de um sifão da lâmina (E-G- Microscopia Eletrônica de Varredura).

Encontrado no mediolitoral, nas poças, em substrato arenoso e rochoso, e no infralitoral, em substrato arenoso e biodetrítico, alcançando profundidades de até $26 \mathrm{~m}$. Udotea cyathiformis var. flabellifolia difere da variedade típica apenas pela lâmina em forma de leque. Morfológica e anatomicamente, os exemplares analisados estão de acordo com Littler \& Littler (1990).

Material examinado - Banco Royal Charlotte, Estação 2C, $15^{\circ} 38^{\prime} 55^{\prime}$ 'S, 38 $35^{\circ} 40^{\prime}$ 'W, 19 out. 1997, Projeto Revizee (RFA 28105); Camaçari, \#C5, $12^{\circ} 46^{\prime} 15^{\prime} \mathrm{S}, 38^{\circ} 05^{\prime} 55^{\prime \prime} \mathrm{W}$, jan. 2009,
CETREL (ALCB 98177); \#D5, 12 $42^{\circ} 40,49^{\prime \prime} \mathrm{S}, 38^{\circ} 07^{\prime} 16,25^{\prime \prime} \mathrm{W}$, fev. 2011, CETREL (ALCB 106978); \#E4, 1247’31,05”'S, $38^{\circ} 07^{\prime} 58^{\prime}$ 'W, jan. 2013, CETREL (ALCB 107097); Vera Cruz, Praia da Penha, 16 nov. 2012, G.N. Santos et al. (ALCB 103690).

\subsection{Udotea dixonii D.S.Littler \& M.M.Littler,} Phycologia 29(2): 220. 1990

Figuras 12 e 13.

Talo calcificado, verde, ereto, até $17 \mathrm{~cm}$ alt., crescendo isoladamente ou em grupos de até 5 indivíduos. Apressório bulboso; estipe cilíndrico, liso, 


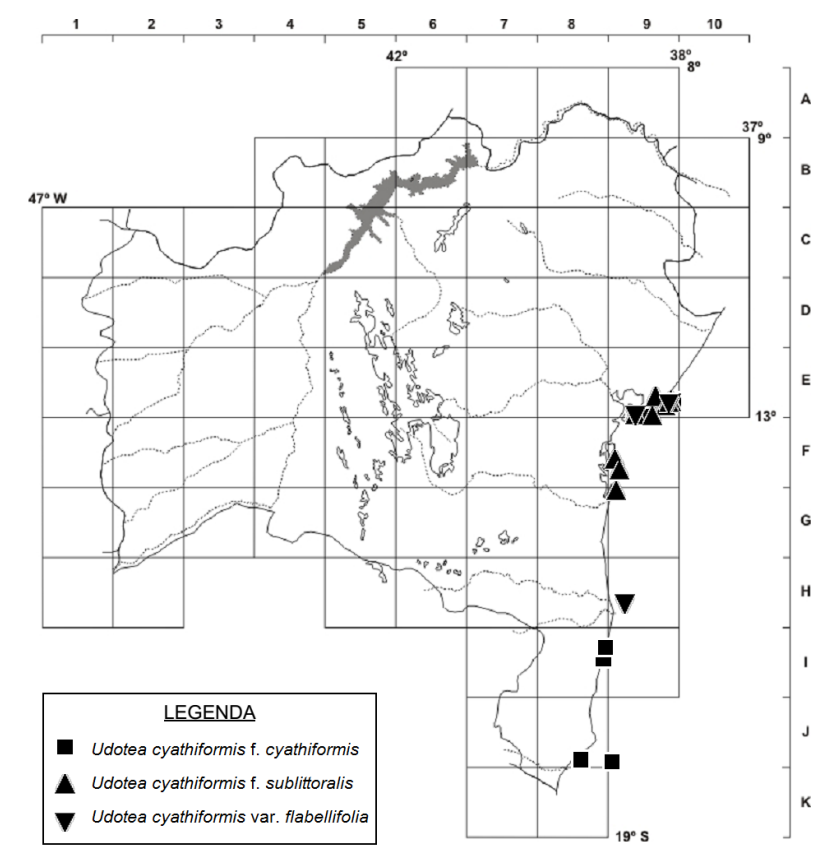

Figura 9. Mapa de distribuição dos táxons infraespecíficos de Udotea cyathiformis no litoral do estado da Bahia.

não ramificado, 0,4-3 cm compr., 0,5-2 mm diâm.; lâmina, grande, lisa, coriácea, lobada, cujos lobos se intercalam com prolongamentos estreitos, 3,8-14 cm compr., 2,5-5 cm larg., 2-8 mm espessura, com linhas de crescimento que lhes conferem uma zonação distinta. Sifões da região medular da lâmina cilíndricos ou levemente moniliformes, densamente revestidos por duas fileiras verticais de apêndices laterais aos pares, 20-35 $\mu \mathrm{m}$ diâm., constrições desiguais acima das dicotomias; apêndices sifonais formando a região cortical da lâmina. Sifões da região medular do estipe 40-56 $\mu \mathrm{m}$ diâm., não constritos acima das dicotomias, com apêndices laterais unidos formando a região cortical. Apêndices da lâmina e do estipe opostos, raramente alternados. Não foram observados exemplares férteis.

Encontrado predominantemente no infralitoral, entre 23 e $50 \mathrm{~m}$ de profundidade, em substrato arenoso e cascalho biodetrítico, no mediolitoral, nas poças, em substrato arenoso e rochoso, e na região frontal do recife, em substrato rochoso. Assemelha-se a $U$. flabellum e é provável que exemplares dessa espécie coletados antes de sua publicação tenham sido identificados equivocadamente naquela espécie. Apesar das semelhanças quanto à morfologia externa do talo, $U$. dixonii frequentemente ocorre em grupos com 2 a 5 indivíduos partindo da mesma massa rizoidal, enquanto $U$. flabellum tem uma lâmina mais rígida e áspera e ocorre isoladamente. A maioria dos representantes de $U$. dixonii foi encontrada entre $23 \mathrm{e}$ $50 \mathrm{~m}$ de profundidade, enquanto os representantes de U. flabellum foram encontrados no mediolitoral. As duas espécies são algumas vezes encontradas simpatricamente na extensão de profundidade mais inferior de $U$. flabellum e no limite superior de $U$. dixonii (quase $15 \mathrm{~m}$ de profundidade) (Littler \& Littler 1990). Anatomicamente, $U$. dixonii apresenta muitos apêndices regularmente dispostos, enquanto em $U$. flabellum, eles são menos numerosos e as ramificações são mais abertas. Anatomicamente, os exemplares analisados estão de acordo com as descrições de Littler \& Littler $(1990,2000)$ e Collado-Vides et al. (2009), porém são menores que os exemplares do Caribe, que chegam a $21 \mathrm{~cm}$ de altura (Littler \& Littler 1990, 2000) e maiores que os exemplares estudados por ColladoVides et al. (2009), que apresentaram até $11 \mathrm{~cm}$ de altura.

Material selecionado - Baixo Sul, Estação 11, 1402'49,2”S, $38^{\circ} 52^{\prime} 58,6$ 'W, 8 jan. 2004, ENSR (ALCB 61084); Carevelas, Cordão ente Redonda e Siriba, 27 nov. 1984, M.A.O.F. Guerra (ALCB 107139, RB 228246); Ilha Redonda, jul. 1987, M. Oliveira (SPF 53684); Camaçari, \#C9, 1247'50”S, 3803'38,59”W, jul. 2000, CETREL (HUNEB 11110); Arembepe, 10 set. 1993, Cepemar (ALCB 22156); Porto Seguro, Arraial d'Ajuda, 21 fev. 1981, G.J.P. Mitchell (ALCB 107133, RFA 952); Mucugê, 12 mar. 2001, J.M.C. Nunes, et al. (ALCB 52971); Saubara, 24 abr. 2001, G.M. Amado Filho (ALCB 86240, RB 464066); Salvador, Estação OC-12, 1258'33,4”S, 38²2'16,6”W, 17 jan. 2003, EMBASA (ALCB 60712); Praia de Itapuã, 20 abr. 1987, G.J.P. Mitchell (ALCB 107115, RFA 5116); 14 nov. 2012, G.N. Santos \& L.M.S. Cruz (ALCB 103737); 8 maio 2013, G.N. Santos et al. (ALCB 107163).

3.4. Udotea flabellum (J. Ellis \& Sol.) J.V. Lamour., Bull. Torry Bot. Club 31: 94. 1904. Corallina flabellum J. Ellis \& Sol., Bull. Torry Bot. Club. 124, pl. 24. 1786.

Figuras 14 e 15.

Talo calcificado, verde-claro a verde-escuro, ereto, solitário, até $12 \mathrm{~cm}$ alt. Apressório bulboso; estipe cilíndrico, sem ramificações, 0,5-2 cm compr., 0,5-5 $\mathrm{mm}$ diâm.; lâmina, flabeliforme, frequentemente recortada ou rasgada, rígida e áspera, até $10 \mathrm{~cm}$ compr., 3-12 cm larg., 1-2 $\mathrm{mm}$ espessura, eventualmente marcada por linhas de crescimento. Sifões medulares da lâmina 28-44 $\mu \mathrm{m}$ diâm., dicotômicos, constritos ou não acima das dicotomias, com ápices arredondados e apêndices sifonais escassos, alternados. Sifões da região medular do estipe 20-60 $\mu \mathrm{m}$ diâm., dicotômicos, constritos ou não acima das dicotomias, com apêndices de ápices truncados, formando a região cortical. Não foram observados exemplares férteis.

Encontrada no mediolitoral, em poças, em substrato arenoso e rochoso, e no infralitoral, em substrato arenoso e biodetrítico, alcançando a profundidade de cerca de $27 \mathrm{~m}$. Anatomicamente, os exemplares analisados estão de acordo com Littler \& Littler (1990, 2000) e Collado-Vides et al. (2009), mas são consideravelmente menores quando comparados aos exemplares do Caribe, que chegam a $30 \mathrm{~cm}$ de altura (Littler \& Littler 1990, 2000), e ao descritos por Collado-Vides et al. (2009), que chegaram a $17 \mathrm{~cm}$ de altura. 


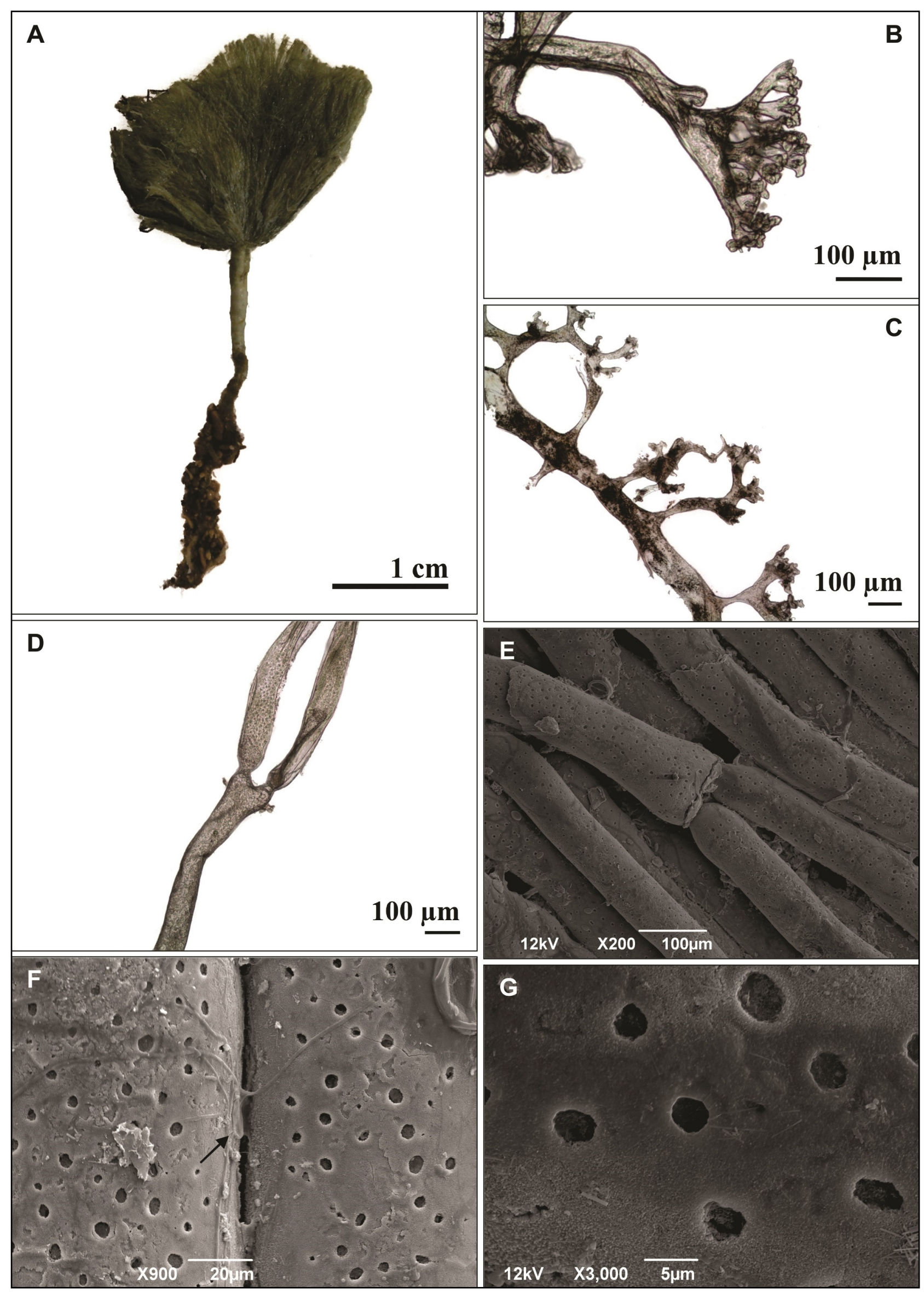

Figura 10. Udotea cyathiformis var. cyathiformis f. sublittoralis: A- aspecto geral; B- sifão do estipe; C- detalhe de um apêndice lateral do estipe; D- dicotomia do sifão da lâmina E- detalhe de um sifão da lâmina e dicotomia; F- detalhe da soldadura formada pelo carbonato de cálcio entre os sifões da lâmina (seta); G- detalhe dos numerosos poros de um sifão da lâmina (E-G- Microscopia Eletrônica de 


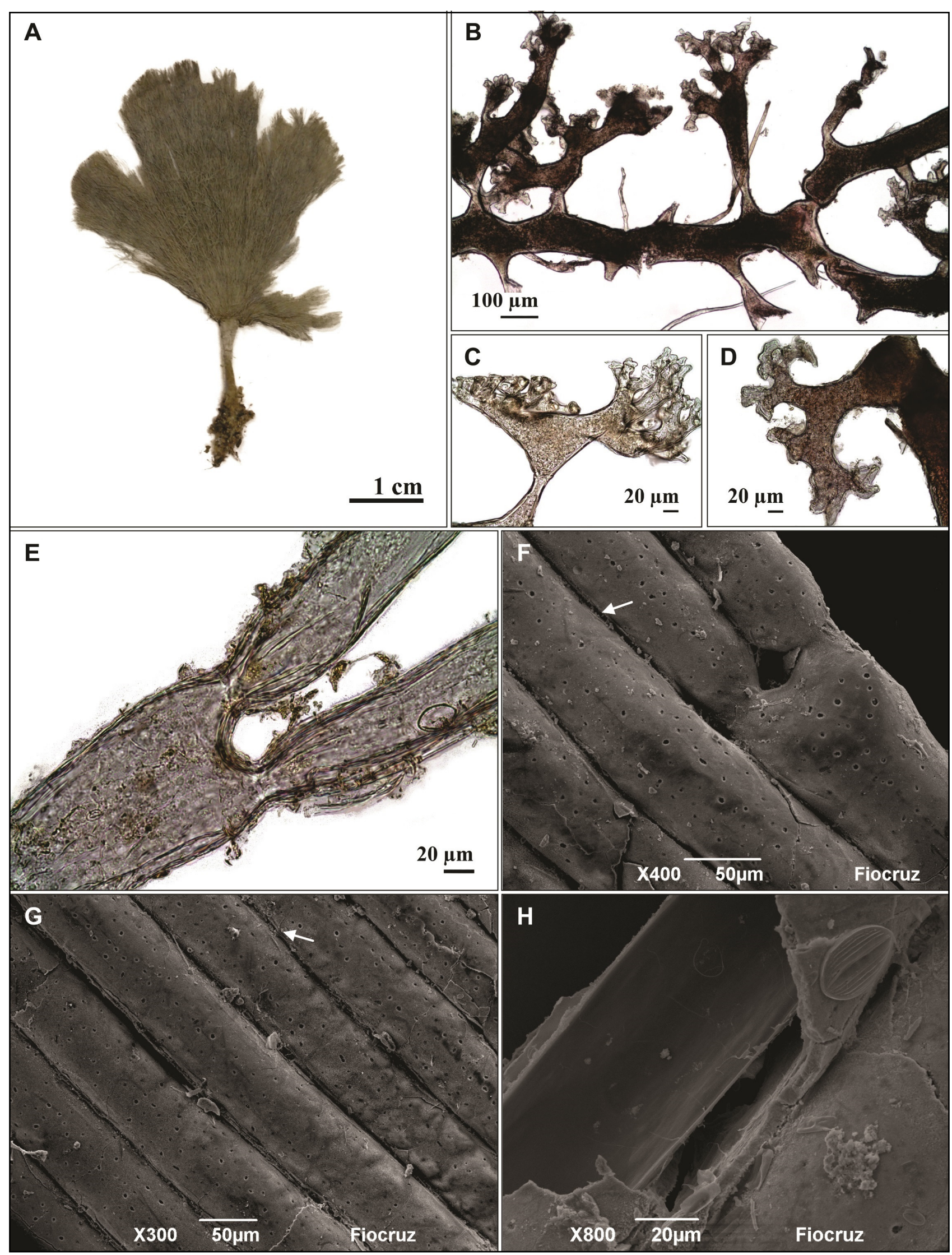

Figura 11. Udotea cyathiformis var. flabellifolia: A- aspecto geral; B- sifão do estipe; C e D- apêndice lateral do estipe; E- dicotomia de um sifão da lâmina; F e G- sifões da lâmina com detalhe para a soldagem de carbonato de cálcio entre os sifões da lâmina e numerosos poros na capa calcária (setas); H- detalhe da capa calcária de um sifão da lâmina. (F-H- Microscopia Eletrônica de Varredura). 


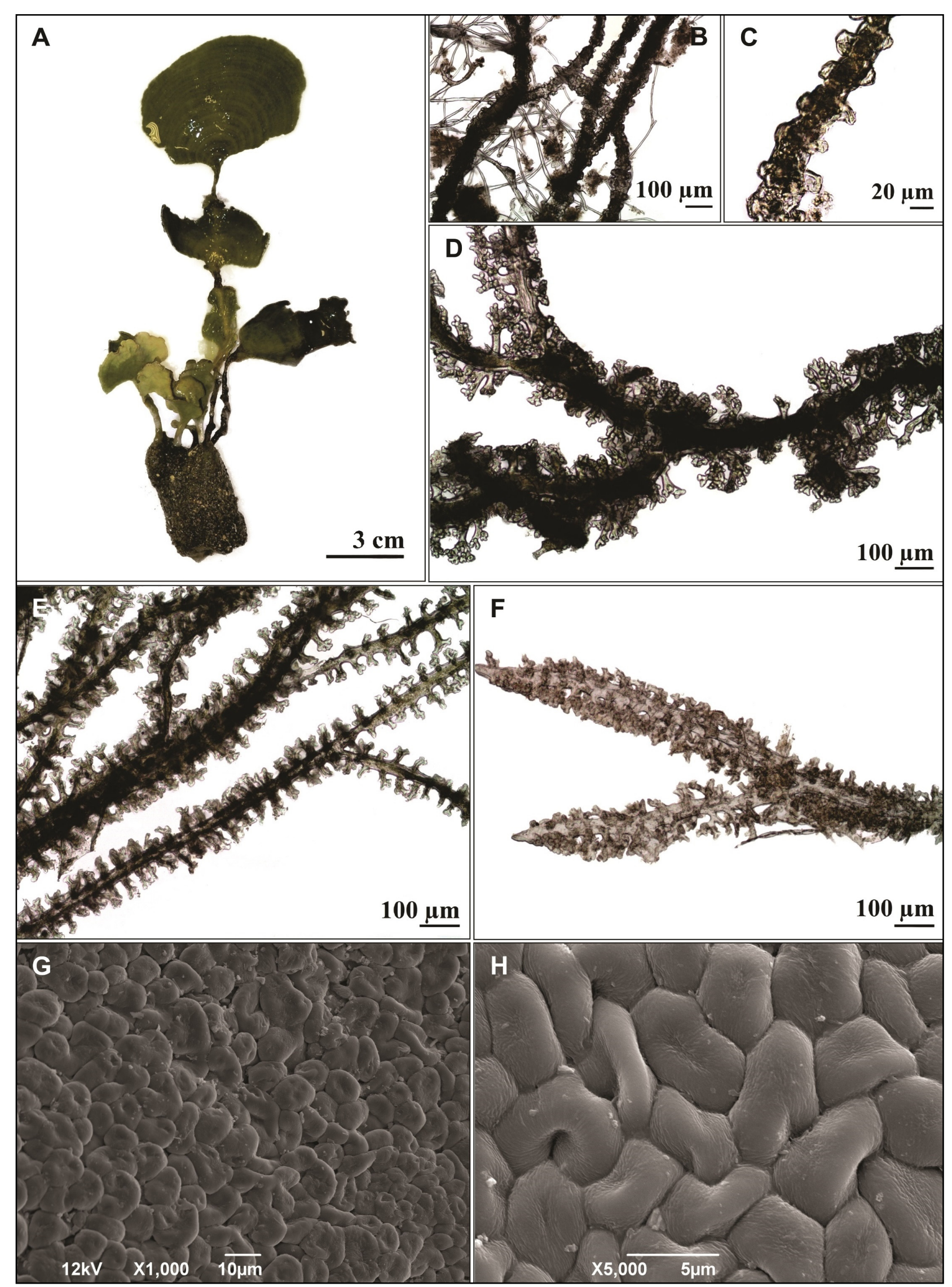

Figura 12. Udotea dixonii: A- aspecto geral; B e C- rizoides; D- dicotomia em um sifão do estipe; E- sifões da lâmina; F- detalhe da dicotomia de um sifão da margem de crescimento da lâmina; G e H- detalhe da superfície da lâmina mostrando apêndices laterais (Microscopia Eletrônica de Varredura). 


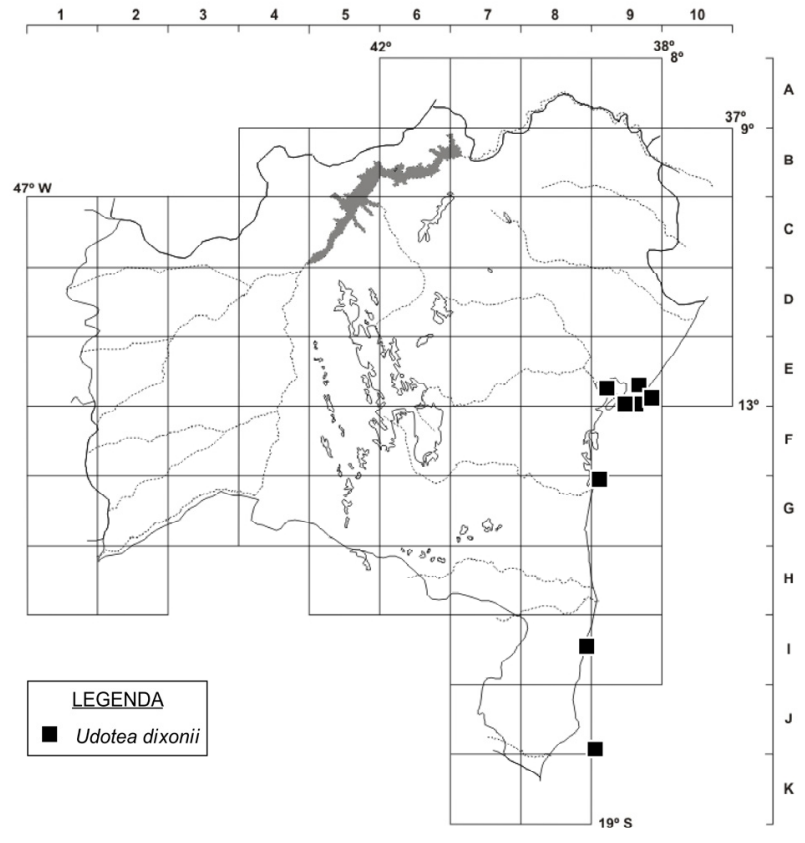

Figura 13. Mapa de distribuição de Udotea dixonii no litoral do estado da Bahia.

Material examinado - Caravelas, Ilha da Siriba, 27 nov. 1984, G.J.P. Mitchell (RFA 1714); Ilha Redonda, 1 dez. 1982 M.L. Christoffersen (JPB 11057); Recife da Lixa, 11 abr. 1964, A.B. Joly et al. (ALCB 48231); Cairu, Morro de São Paulo, 26 ago, 2000, J.M.C. Nunes (ALCB 53223, HUNEB 10101); Camaçari, \#A4, 12\%44'12,03”S, 3805’12,53”'W, 2010.1, CETREL (ALCB 99832); Nova Viçosa, 18 abr. 1988, G.J.P. Mitchell (RFA 4446); Arrecifes, 15 dez. 1985, G.J.P. Mitchell (RFA 2052); Ilha de Coroa Vermelha, 15 dez. 1985, G.J.P. Mitchell (RFA 2055); 9 mar. 2001, J.M.C. Nunes (ALCB 53535); 3 jun. 2012 T.A. Caires (ALCB 103488); Porto Seguro, Enseada do Mutá, 22 fev. 1981, G.J.P. Mitchell (RFA 935); Mucugê, 12 mar. 2001, J.M.C. Nunes et al. (ALCB 52971, HUNEB 8393); 5 jun. 2012, T.A. Caires (ALCB 103466); Salvador, Praia de Patamares, 29 jun. 1984, E.J. Marques (ALCB 17390); Praia de Placafor, 20 dez. 1984, G.P. Borges (ALCB 17220); 22 jul. 2013 G.N. Santos (ALCB 109558); Praia do Rio Vermelho, out. 1968, D.C. Martins (ALCB 17023); Santa Cruz Cabrália, Coroa Alta, 3 jan. 1979, E.C. Oliveira (SPF 51167); Ponta de Coroa Vermelha, 15 out. 1982, M.L. Christoffersen (JPB 11054); Ponta do Mutá, 16 out. 1982, A.I. Kanagawa (JPB 11053); Vera Cruz, Barra do Pote, 28 nov.1989, A.P. Nunes (ALCB 17192); 31 jul. 1997, J.M.C. Nunes (ALCB 48401); Praia da Penha, 27 set. 1996, J.M.C. Nunes (ALCB 22389); 16 out. 2012, G.N. Santos et al. (ALCB 103483).

\section{CONSIDERAÇõES FINAIS}

Com o presente estudo, foi possível identificar os caracteres com importância taxonômica. Caracteres morfológicos, com destaque para a presença de calcificação, o hábito, a estrutura do talo e o tipo de apressório, são mais úteis para a identificação no nível de família e gênero, enquanto os anatômicos, como a

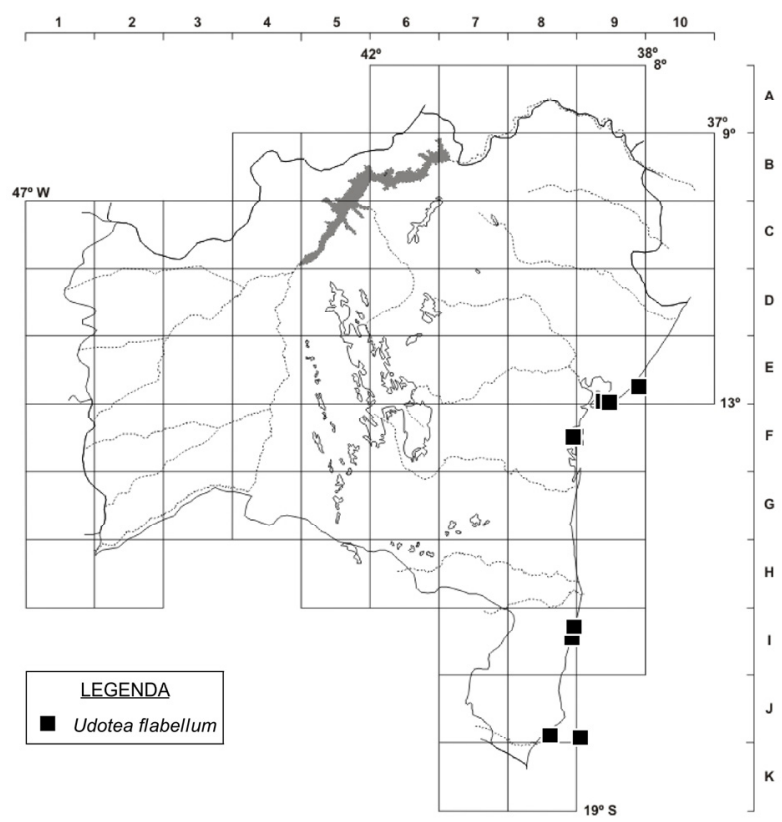

Figura 14. Mapa de distribuição de Udotea flabellum no litoral do estado da Bahia.

forma, o diâmetro e o tipo de ramificação dos sifões, juntamente com as fusões nos filamentos e o tipo e forma dos apêndices laterais, utrículos ou tenáculas, permitem identificações mais precisas, bem como a solução de conflitos taxonômicos.

A microscopia eletrônica de varredura mostrou-se valiosa na identificação de Udoteaceae por permitir a visualização de caracteres anatômicos que não podem ser vistos em microscopia de luz, a qual exige descalcificação dos espécimes.

Penicillus capitatus f. elongatus e P. capitatus $\mathrm{f}$. laxus são registrados pela primeira vez no litoral brasileiro. A ocorrência na Bahia dos gêneros Pseudocodium e Rhipidosiphon (Bravin et al. 1999) e de Udotea caribaea e U. occidentalis (YoneshigueValentin et al. 2006), por outro lado, necessitam de confirmação.

\section{AGRADECIMENTOS}

Ao Programa de Pós-Graduação em Biodiversidade Vegetal pelo apoio financeiro às coletas; ao Laboratório de Algas Marinhas (LAMAR) do Instituto de Biologia da UFBA e ao Herbário Alexandre Leal Costa (ALCB) pela disponibilidade da infraestrutura; ao Centro de Pesquisas Gonçalo Muniz da Fundação Oswaldo Cruz (FIOCRUZ) pela disponibilidade do uso do microscópio eletrônico de varredura; aos herbários brasileiros que disponibilizaram seus exemplares para a pesquisa; e ao Programa de Apoio a Núcleos Emergentes (PRONEMFAPESB, T.O.PNE 0020/2011). 


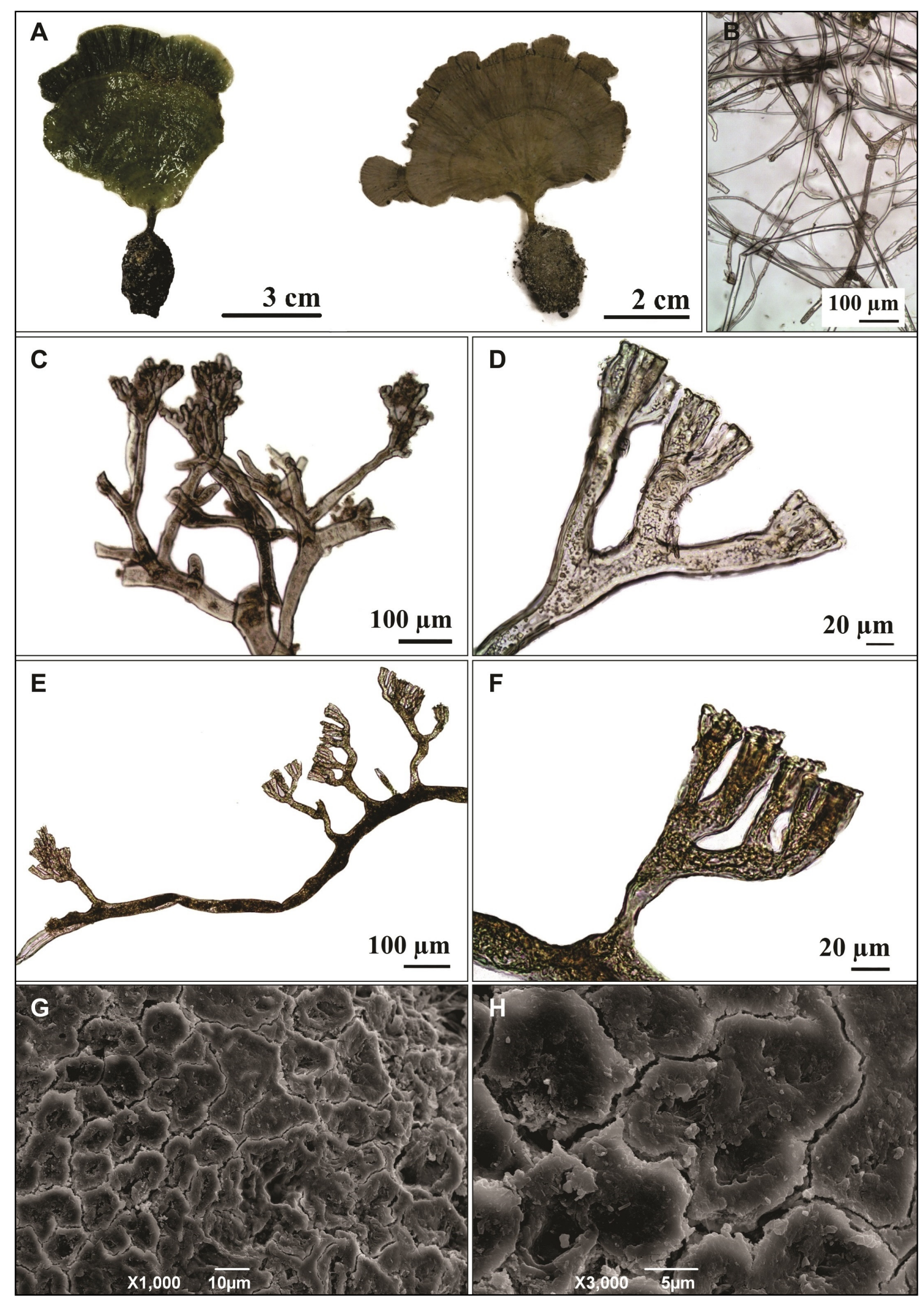

Figura 15. Udotea flabellum: A- aspecto geral; B- detalhe dos filamentos rizoidais; C- sifão do estipe; D- apêndice de um sifão do estipe; Esifão da lâmina; F- apêndice de um sifão da lâmina; G e H- detalhe da superfície da lâmina mostrando apêndices laterais (Microscopia Eletrônica de Varredura). 


\section{REFERÊNCIAS}

Afonso-Carrillo, J.; Pérez, L.; Sansón, M. \& Reyes, J. 1998 Observaciones em Tricleocarpa cylindrica com el microscopio electrónico de barrido (Rhodophyta, Galaxauraceae). Vieraea 26: 87-91.

Altamirano, M. \& Nunes, J.M.C. 1997. Contribuiciones al macrofitobentos del município de Camaçari (Bahia, Brasil). Acta Botanica Malacitana 22: 211-215.

Amorim, P.R.R.; Moura, C.W.N. \& Moniz-Brito, K.L. 2006. Estudo morfo-taxonômico das espécies de Halimeda, Penicillus e Udotea (Bryopsidales, Chlorophyta) do recife de franja da Ilha de Itaparica, Bahia. In: Anais do Congresso Brasileiro de Ficologia e Simpósio Latino-Americano Sobre Algas Nocivas, 11. Itajaí, p. 35-54.

Andrade, N.A. 2012. O Papel da Declividade e Sedimentologia na Composição e Estrutura dos Bancos de Rodolitos do Litoral Norte da Bahia, Brasil. Dissertação de Mestrado. Universidade do Estado da Bahia.

Bandeira-Pedrosa, M.E.; Pereira, S.M.B. \& Oliveira, E.C. 2004a. Taxonomy and distribution of the green algal genus Halimeda (Bryopsidales, Chlorophyta) in Brazil. Revista Brasileira de Botânica 27(2): 363-377.

Bandeira-Pedrosa, M.E.; Pereira, S.M.B.; Bouzon, Z.L. \& Oliveira, E.C. 2004b. Halimeda cuneata (Bryopsidales, Chlorophyta), a new record for the Atlantic Ocean. Phycologia 43(1): 50-57.

Barata, D. 2004. Cloroficeas Marinhas Bentônicas do Estado do Espírito Santo. Dissertação de Mestrado. Instituto de Botânica da Secretaria de Estado do Meio Ambiente.

Borowitzka, M.A. \& Larkum, A.D.W. 1977. Calcification in the green algae Halimeda, an ultrastructure study of thallus development. Journal of Phycology 16: 6-16.

Bravin, I.C.; Torres, J.; Gurgel, C.F.D. \& Yoneshigue-Valentin, Y. 1999. Novas ocorrências de clorofíceas marinhas de profundidade para o Brasil. Hoehnea 26: 121-133.

Cabrera, R. \& Alfonso, Y. 2010. Notas sobre el género Penicillus (Udoteaceae, Chlorophyta) para Cuba. Revista del Jardín Botánico Nacional 30: 239-244.

Calderón-Saénz, E. \& Schnetter, R. 1989. The life histories of Boodleopsis vaucherioidea sp. nov. and B. pusilla (Caulerpales) and their phylogenetic implications. Phycologia 28(4): 476490.

Cassano, V.; Brito, L.V.R. \& Széchy, M.T.M. 2004. The occurrence of Boodleopsis vaucherioidea Calderón-Sáenz et Schnetter (Udoteaceae, Chlorophyta) in Brazil. Botanica Marina 47: 251-254.

Clifton, K.E. \& Clifton, L.M. 1999. The phenology of sexual reproduction by green algae (Bryopsidales) on Caribbean coral reefs. Journal of Phycology 35: 24-34.

Collado-Vides, L.; Suárez, A.M. \& Cabrera, R. 2009. Una revisión taxonómica del género Udotea en el Caribe mexicano y cubano. Revista de Investigaciones Marinas 30(2): 145-161.

Costa, I.O. 2013. Estudos taxonômicos em algas coralináceas não articuladas no Litoral Norte da Bahia, Brasil. Dissertação de Mestrado. Universidade do Estado da Bahia.

Costa, I.O.; Caires, T.A.; Pereira Filho, G.H. \& Nunes, J.M.C. 2012. Macroalgas bentônicas associadas a bancos de Hypnea musciformis (Wulfen) J.V. Lamour. (Rhodophyta Gigartinales) em duas praias do litoral baiano. Acta Botanica Brasilica 26(2): 493-507.

Curtis, C.E.; Dawes, C.J. \& Pierce, S.K. 2008. Phylogenetic analysis of the large subunit rubisco gene supports the exclusion of Avrainvillea and Cladocephalus from the Udoteaceae (Bryopsidales, Chlorophyta). Journal of Phycology 44: 761767.

DeWreede, R. 2006. Biomechanical properties of coenocytic algae (Chlorophyta, Caulerpales). Science Asia 1(32): 57-62.

Garbary, D.J. \& Johansen, H.W. 1982. Scanning electron microscopy of Corallina and Haliptilon (Coralinaceae, Rhodophyta): surface features and their taxonomic implications. Journal of Phycology 18: 211-219.

Gepp, A. \& Gepp, E.A. 1911. The Codiaceae of the Siborga Expedition Including a Monograph of Flabellarieae and Udotea. Siborga-Ecpedite Monographie 62. E. J. Brill, Leiden.

Guiry, M.D. \& Guiry, G.M. 2014. AlgaeBase. World-wide electronic publication, National University of Ireland, Galway, Disponível em http://www.algaebase.org; acesso em 4 jul. 2014.

Hillis-Colinvaux, L. 1986. Distribution patterns of some Bryopsidales in the geologic past: their bearing on present distributions. Botanica Marina 29: 271-277.

Joly, A.B. 1967. Gêneros de Algas Marinhas da Costa Atlântica Latino-Americana. Editora da Universidade de São Paulo, São Paulo.

Kooistra, W.H.C.F. 2002. Molecular phylogenies of Udoteaceae (Bryopsidales, Chlorophyta) reveal nonmonophyly for Udotea, Penicillus and Chlorodesmis. Phycologia 41(5): 453-462.

Lam, D.W. \& Zechman, F.W. 2006. Phylogenetic analyses of the Bryopsidales 7 (Ulvophyceae, Chlorophyta) based on RUBISCO large subunit gene sequence. Journal of Phycology 42: 669-678.

Littler, D.S. \& Littler, M.M. 1990. Systematics of Udotea species (Bryopsidales, Chlorophyta) in the tropical weastern Atlantic. Phycologia 29(2): 206-252.

Littler, D.S. \& Littler, M.M. 1992. Systematics of Avrainvillea (Bryopsidales, Chlorophyta) in the tropical western Atlantic. Phycologia 31(5): 375-418.

Littler, D.S. \& Littler, M.M. 2000. Caribbean Reef Plants. OffShore Graphics, Washington.

Marins, B.V.; Braliseiro, P.S.; Barreto, M.B.B.; Nunes, J.M.C.; Yoneshinge-Valentin, Y. \& Amado Filho, G.M.A. 2008. Subtidal benthic marine algae of The Todos os Santos Bay, Bahia State, Brazil. Oecologia Brasiliensis 12(2): 229-242.

Martins, D.V.; Cordeiro-Marino, M.; Boccanera, N.B. \& Nunes, J.M.C. 1991. Clorofíceas marinhas bentônicas do Município de Salvador, Bahia, Brasil. Hoehnea 18(2): 115-133.

Moura, C.W.N. 2014. Bryopsidophyceae. In: Lista de Espécies da Flora do Brasil. Jardim Botânico do Rio de Janeiro. Disponível em <http://floradobrasil.jbrj.gov.br/>; acesso em 22 Jan. 2014.

Nunes, J.M.C. 1998. Catálogo de algas marinhas bentônicas do Estado da Bahia. Acta Botanica Malacitana 23: 5-21.

Nunes, J.M.C. 2005. Rodoficeas Marinhas Bentônicas do Estado da Bahia, Brasil. Tese de Doutorado. Universidade de São Paulo.

Nunes, J.M.C. 2010. Taxonomia morfológica: Metodologia de trabalho. In: A.G. Pedrini (org.), Macroalgas: uma introdução à taxonomia. Technical Books, Rio de Janeiro, p. 53-70. 
Nunes, J.M.C.; Santos, A.C.C.; Minervino, A. \& Brito, K.S. 1999. Algas marinhas bentônicas do município de Ilhéus, Bahia, Brasil. Acta Botanica Malacitana 24: 5-12.

Nunes, J.M.C.; Santos, A.C.C.; Lyra, G.M.; Minervino-Netto, A. \& Pedreira, E.S. 2001. Marine benthic algae from Uruçuca, Bahia, Brazil. Acta Botanica Malacitana 26: 181-246.

Reis-Santos, R.P. 1990. Flora Algal da Lagoa de Araruama. Dissertação de Mestrado. Universidade Federal do Rio de Janeiro.

Ries, J.B. 2005. Aragonite production in calcite seas: effect of seawater $\mathrm{Mg} / \mathrm{Ca}$ ratio on the calcification and growth of the calcareous alga Penicillus capitatus. Paleobiology 31(3): 445458.

Rogers, R.W. 1996. Spatial, seasonal, and secular patterns in the cover of green algae on Heron Reef Flat, Great Barrier Reef, Australia. Botanica Marina 39: 415-419.

Taylor, W.R.; Joly, A.B. \& Bernatowicz, A.J. 1953. The relation of Dichotomosiphon pusillus to the algal genus Boodleopsis. Michigan Academy of Science, Arts, and Letters 38: 97-113.

Santos, G.N.; Nascimento, O.S.; Pedreira, F.A.; Rios, G.I.; Vasconcelos, J.N.C. \& Nunes, J.M.C. 2013. Análise quali- quantitativa das algas arribadas do norte do estado da Bahia, Brasil. Acta Botanica Malacitana 38: 13-24.

Verbruggen, H.; Ashworth, M.; Loduca, S.T.; Vlaeminck, C.; Cocquyt, E.; Sauvage, T.; Zechman, F.W.; Littler, D.S.; Littler, M.M.; Leliaert, F. \& Clerck, O. 2009. A multi-locus time-calibrated phylogeny of the siphonous green algae. Molecular Phylogenetics and Evolution 50: 642-653.

Vroom, P.S.; Smith, C.M. \& Keeley, S.C. 1998. Cladistics of the Bryopsidales: a preliminary analysis. Journal of Phycology 34: 351-360.

Wynne, M.J. 2011. A checklist of the benthic marine algae of the tropical and subtropical western Atlantic: third revision. Nova Hedwigia 140: 1-166.

Yoneshigue-Braga, Y. 1970. Flora marinha bentônica da Baía de Guanabara e cercanias. I. Chlorophyta. Publicações do Instituto de Pesquisa da Marinha 42: 1-55.

Yoneshigue-Valentin, Y.; Gestinari, L.M.S. \& Fernandes, D.R.P. 2006. Macroalgas. In: H.P. Lavrado \& B.L. Ignacio (eds), Biodiversidade Bentônica da Região Central da Zona Exclusiva Brasileira. Museu Nacional, Rio de Janeiro, p. 67105 .

\section{LISTA DE EXSICATAS}

Amado-Filho, G.M. s.n. ALCB: 86240 (3.5), 90638 (3.2), 90788 (3.3), RB: 375337 (1.1), 464066 (3.5), 464068 (3.2); Borges, G.P. s.n. ALCB: 17220 (3.6); Caires, T.A. s.n. ALCB: 103466 (3.6), 103470, 103472 (3.2), 103488 (3.6); CETREL s.n. ALCB: 48234 (3.3), 48246 , 48247, 48250, 49197 (3.5), 49556 (3.3), 53264 (3.5), 57446, 60720 (3.3), 60730 (3.2), 60754, 68350 (3.5), 81174, 81178 (3.3), 98177 (3.4), 98178, 98180, 99825 (2.3), 99832 (3.6), 99903 (3.3), 100296, 100371,100409 (3.5), 100490 (3.2), 103763, 103776 (3.5), 106975,106977 (3.3), 106978 (3.4), 107079-107081, 107085 (3.5), 107092, 107096 (3.3), 107097 (3.4), 107098, 107117, 109516 (3.3), 110230 (3.5), 110232 (2.3), 110235 (3.3), HUNEB: 11110 (3.5); Christoffersen, M.L. s.n. JPB: 11054, 11057 (3.6), RFA: 1574 (2.1); Cepemar s.n. ALCB: 22155 (3.3), 22156 (3.5); Costa Junior, O.S. s.n. ALCB: 48205 (3.2); EMBASA s.n. ALCB: 60708 (3.3), 60712 (3.5); ENSR s.n. ALCB: 61080 (3.3), 61084 (3.5), 61087, 61102 (3.3); Guerra, M.A.O.F. s.n. ALCB: 107139 (3.5), RB: 228245 (2.1), 228246 (3.5), 228285 (3.2), 228286 (2.1); Joly, A.B. s.n. ALCB: 48223 (3.2), 48231 (3.6), 48233, SP-Algae: 96119 (3.2), 96210 (2.1); Kanagawa, A.I. s.n. JPB: 11053 (3.6); Marques, E.J. s.n. ALCB: 17390; Martins, D.C. s.n. ALCB: 17023 (3.6); Mitchell, G.J.P. s.n. ALCB: 107115, 107133 (3.5), RFA: 935 (3.6), 952 (3.5), 1714 (3.6), 1722 (2.1), 2052, 2055 (3.6), 2056 (2.1), 4446 (3.6), 4459, 4492 (2.1), 5116 (3.5), 6661 (3.2); Nonato, E. s.n. SPF: 694 (2.1), 4414 (3.2); Nunes, A.P. s.n. ALCB: 17192 (3.6), 17197 (2.1); Nunes, J.M.C. s.n. ALCB: 22235 (2.1), 22389 (3.6), 32303 (1.1), 48401 (3.6), 49457 (2.1), 49473 (3.2), 52971 (3.5), 52989 (3.2), 53223,53535 (3.6), 68419, 68457 (2.1), 103478 (2.2), 103537 , 103696 (2.1), HUNEB: 8353 (3.2), 8393 (3.5), 10101 (3.6); Oliveira, A.E.S. s.n. RB: 353632 (2.1); Oliveira, E.C. s.n. SPF: 51167 (3.6); Oliveira, M. s.n. SPF: 53663 (2.1), 53684 (3.5); Ramos, M.E.C. s.n. ALCB: 53437 (2.1); Projeto Revizee s.n. RFA: 28105 (3.4), 28108, 28110, 28111 (3.1); Santos, G.N. s.n. ALCB: 103483 (3.6), 103500 (3.2), 103690 (3.4), 103697 (2.1); 103737, 107163, 109558 (3.5). (3.3). 